\title{
Effects of undernutrition on mortality and morbidity among adults living with HIV in sub-Saharan Africa: a systematic review and meta-analysis
}

\author{
Animut Alebel ${ }^{1,2^{*}}$ (D), Daniel Demant ${ }^{2,3}$, Pammla Petrucka $^{4,5}$ and David Sibbritt ${ }^{2}$
}

\begin{abstract}
Background: Undernutrition is one of the most common problems among people living with HIV, contributing to premature death and the development of comorbidities within this population. In Sub-Saharan Africa (SSA), the impacts of these often inter-related conditions appear in a series of fragmented and inconclusive studies. Thus, this review examines the pooled effects of undernutrition on mortality and morbidities among adults living with HIV in SSA.

Methods: A systematic literature search was conducted from PubMed, EMBASE, CINAHL, and Scopus databases. All observational studies reporting the effects of undernutrition on mortality and morbidity among adults living with HIV in SSA were included. Heterogeneity between the included studies was assessed using the Cochrane Q-test and $I^{2}$ statistics. Publication bias was assessed using Egger's and Begg's tests at a 5\% significance level. Finally, a random-effects metaanalysis model was employed to estimate the overall adjusted hazard ratio.

Results: Of 4309 identified studies, 53 articles met the inclusion criteria and were included in this review. Of these, 40 studies were available for the meta-analysis. A meta-analysis of 23 cohort studies indicated that undernutrition significantly (AHR: $2.1,95 \% \mathrm{Cl}: 1.8,2.4$ ) increased the risk of mortality among adults living with HIV, while severely undernourished adults living with HIV were at higher risk of death (AHR: $2.3,95 \% \mathrm{Cl}: 1.9,2.8$ ) as compared to mildly undernourished adults living with HIV. Furthermore, the pooled estimates of ten cohort studies revealed that undernutrition significantly increased the risk of developing tuberculosis (AHR: $2.1,95 \% \mathrm{Cl}: 1.6,2.7$ ) among adults living with HIV.

Conclusion: This review found that undernutrition has significant effects on mortality and morbidity among adults living with HIV. As the degree of undernutrition became more severe, mortality rate also increased. Therefore, findings from this review may be used to update the nutritional guidelines used for the management of PLHIV by different stakeholders, especially in limited-resource settings.
\end{abstract}

Keywords: Adults living with HIV, PLHIV, Sub-Saharan Africa, Undernutrition

\footnotetext{
* Correspondence: animut.a23@gmail.com

'College of Health Science, Debre Markos University, Debre Markos, Ethiopia

${ }^{2}$ School of Public Health, Faculty of Health, University of Technology Sydney, Ultimo, NSW, Australia

Full list of author information is available at the end of the article
}

C C The Author(s). 2021 Open Access This article is licensed under a Creative Commons Attribution 4.0 International License, which permits use, sharing, adaptation, distribution and reproduction in any medium or format, as long as you give appropriate credit to the original author(s) and the source, provide a link to the Creative Commons licence, and indicate if changes were made. The images or other third party material in this article are included in the article's Creative Commons licence, unless indicated otherwise in a credit line to the material. If material is not included in the article's Creative Commons licence and your intended use is not permitted by statutory regulation or exceeds the permitted use, you will need to obtain permission directly from the copyright holder. To view a copy of this licence, visit http://creativecommons.org/licenses/by/4.0/ The Creative Commons Public Domain Dedication waiver (http://creativecommons.org/publicdomain/zero/1.0/) applies to the data made available in this article, unless otherwise stated in a credit line to the data. 


\section{Background}

Human Immunodeficiency Virus (HIV) continues to be a significant global public health problem, with SubSaharan Africa (SSA) being the most significantly affected region [1, 2]. Globally, in 2018, an estimated 37.9 million people were living with HIV (PLHIV), and 1.1 million people died from Acquired Immunodeficiency Syndrome (AIDS) related illnesses worldwide [3], with $54 \%$ of PLHIV located in East and Southern Africa, 13\% in Western and Central Africa, $16 \%$ in Asia and Pacific, and 6\% in Western and Central Europe and North America [4]. Low and middle-income countries (LMICs), especially SSA, are the most affected region accounted for $68 \%$ of PLHIV in 2018 [2, 4]. Although there is no cure for HIV, antiretroviral therapy (ART) suppresses viral replication and increases the $\mathrm{CD} 4$ counts sufficiently to improve the survival rates and quality of life [5]. Despite these benefits, 23.3 million (62\%) PLHIV were accessing ART in 2018 $[4,6]$ with low ART coverage in LMICs is mainly attributable to inaccessibility of health coverage [1].

Malnutrition refers to both undernutrition and overnutrition. Undernutrition is a state of inadequate intake of energy or nutrients to support the physiological function of the body. Due to the high prevalence of undernutrition, malnutrition often refers to undernutrition and the associated complications $[7,8]$. Therefore, this review focused on undernutrition, which is the most common form of malnutrition in LMICs.

Despite the use of ART having been effective in reducing AIDS-related mortality and morbidities [9], not all patients living with HIV have the same response to therapy. Thus, additional factors, such as nutritional status, and potential negative effects on the immunologic response of PLHIV must be considered [10]. Undernutrition is the most common problem among PLHIV and a significant factor potentiating morbidities and mortality [10]. Although undernutrition and HIV are global challenges, once more, we see a higher prevalence of undernutrition in SSA [11]. Accordingly, in 2018, about 22.8\% of undernourished people and 68\% of PLHIV were living in SSA $[2,4,12]$.

Undernutrition and HIV are found to be interwoven in a vicious cycle [13]. PLHIV are more vulnerable to developing undernutrition by different mechanisms. HIV is often accompanied by reduction in food intake due to: food insecurity, cognitive impairment or depression, medication-related nausea, and opportunistic infections (OIs) of mouth and oesophagus, which bring about painful swallowing [14]. In addition, HIV increases the energy requirements of HIV-infected adults by $10 \%$ for asymptomatic, and by $20-30 \%$ for symptomatic patients [15]. Conversely, undernutrition weakens the immune system and increases the risk of early mortality and morbidities [16, 17]. Previous studies have shown that undernutrition has a significant impact on mortality and morbidity in PLHIV [18-21], with even a minimal weight loss of up to $5 \%$ significantly increasing the risk of death [22]. Studies conducted elsewhere confirmed that low body mass index (BMI) at ART initiation hastened disease progression and increased the risk of OIs $[9,23]$.

To inform health program planners and policy-makers, current evidence-based findings are required. Although there is a general understanding that undernutrition and HIV are interrelated, a comprehensive systematic review and meta-analysis estimating the pooled effects of undernutrition on mortality and morbidity among adults living with HIV is lacking. Although there are primary studies reporting the effects of undernutrition on mortality and morbidity among adults living with HIV in SSA, they are highly fragmented and inconclusive. For example, some studies showed that undernutrition $\left(\mathrm{BMI}<18.5 \mathrm{~kg}^{2}\right)$ has a significant effect on mortality and morbidity [23-36], while others showed no significant impact on mortality and morbidity [19, 28, 37-40]. To the best of our knowledge, the above inconsistencies have not been well investigated. Therefore, this review aims to examine the effects of undernutrition on mortality and morbidities among adults living with HIV in SSA. Results obtained from this review will provide evidentiary inputs for program planners and decision-makers in designing strategies to reduce undernutrition related mortality and morbidities among PLHIV, particularly in LMICs.

\section{Methods}

\section{Data sources and searching strategies}

This systematic review and meta-analysis is designed to examine the effects of undernutrition on mortality and morbidity among adults living with HIV in SSA. The study protocol for this systematic review was registered in the International Prospective Register of Systematic Reviews (PROSPERO), University of York Centre for Reviews and Dissemination (ID: CRD42020161822). The Preferred Reporting Items for Systematic Reviews and Meta-Analysis (PRISMA) guideline was followed to report our results (Additional file 1) [41]. We searched articles published between 2002 and 2019, aligning with the first year in which the first WHO ART guidelines were distributed for developing countries [42]. A comprehensive search was conducted in the following databases: PubMed (contains MEDLINE), EMBASE (Elsevier), CINA HL (EBSCO), and Scopus (Additional file 2). Searches were limited to articles published in English and conducted on humans. Finally, the reference lists of included studies were screened for additional articles. Articles identified through the electronic search were exported and managed using Covidence, a primary screening and data extraction tool provided by Cochrane. The search from 
the above-mentioned databases was done using the following search terms:

Line1:"malnutrition" OR "undernutrition" OR "nutritional deficienc" OR "malnourish" OR "low Body Mass Index" OR "low BMI" OR "underweight" OR "nutritional status" "stunting" OR "Wasting" OR "underweight" OR "micronutrient deficienc"*".

AND

Line2: "HIV Infections" OR "HIV" OR "HIV-1" OR "HIV-2" OR "HIV infect"” OR "human immunodeficiency virus" OR "human immunedeficiency virus" OR "human immuno-deficiency virus" OR "human immunedeficiency virus" OR "( (human immun")OR (deficiency virus))" OR "acquired immunodeficiency syndrome" OR "acquired immunedeficiency syndrome" OR "acquired immunodeficiency syndrome" OR "acquired immunedeficiency syndrome" OR "((acquired immun*) OR (deficiency syndrome))" OR "HIV-positive" OR "Sexually Transmitted Diseases, Viral".

AND

Line3: "Mortalit"” OR "incidence" OR "survival" OR "death rate" OR "risk factors" OR "time to death" OR "case fatality rate" OR "determinates" OR "mortality rate" OR "predictors" OR "opportunistic infect" "OR "AIDS related opportunistic infecti"” OR "morbidit" OR "hospital admissions" OR "hospitalization" OR "herpes zoster" OR "bacterial pneumonia" OR "pulmonary TB" OR "extra-pulmonary TB" OR "tuberculosis" OR "TB" OR "oral candidiasis" OR "oesophageal candidiasis" OR "mouth ulcer" OR "diarrh" OR "pneumocystis pneumonia" OR "central nervous system toxoplasmosis" OR "toxoplasmosis" OR "cryptococcal meningitis" OR "nonHodgkins lymphoma" OR "Kaposi's sarcoma" OR "cervical cancer" OR "herpes simplex" OR "cytomegalovirus" OR "AIDS defining disease".

AND

Line 4: "Angola" OR "Benin" OR "Botswana" OR "Burkina Faso" OR "Burundi" OR "Cameroon" OR "Cape Verde" OR "Central African Republic" OR "Chad" OR "Comoros" OR "Republic of the Congo" OR "Democratic Republic of the Congo" OR "Cote d'Ivoire" OR "Djibouti" OR "Equatorial Guinea" OR "Eritrea" OR Ethiopia" OR "Gabon" OR "The Gambia" OR "Ghana" OR "Guinea" OR "Guinea-Bissau" OR "Kenya" OR "Liberia" OR "Madagascar" OR "Malawi" OR "Mali" OR "Mauritania" OR "Mauritius" OR "Mozambique" OR "Namibia" OR "Niger" OR "Nigeria" OR "Rwanda" OR "Sao Tome and Principe" OR "Senegal" OR "Seychelles" OR "Sierra Leone" OR "Somalia" OR "South Africa" OR "South Sudan" OR "Sudan" OR "Swaziland" OR "Tanzania" OR "Togo" OR "Uganda" OR "Zambia” OR "Zimbabwe".

The PICO framework was used to determine the eligibility for the study: $\checkmark$ Participants/population: adults (defined as those aged $\geq 15$ years) living with HIV.

$\checkmark$ Intervention(s)/exposure(s) group: undernourished adults living with HIV.

$\checkmark$ Comparator(s)/control group: well-nourished adults living with HIV.

$\checkmark$ Outcomes of interests: mortality and morbidities among adults living with HIV.

\section{Inclusion and exclusion criteria}

The study selection was done by the primary author (AA) using a two-stage approach. Initially, studies were screened based on titles and abstracts. At this stage, all studies reporting mortality and morbidity among PLHIV were considered. Then, a full-text assessment based on the predetermined inclusion criteria was performed (Fig. 1). All observational studies (i.e., cross-sectional, case-control, and cohort) reporting effects of undernutrition on mortality and morbidly among adults living with HIV in SSA were considered for inclusion. However, only cohort studies reporting the adjusted hazard ratio were included in the meta-analysis as determination of cause and effect relationships requires a robust study design. Excluded were systematic reviews, animal studies, studies not reporting the outcome of interests, conference papers, and editorial comments. The reason for excluding conference papers was due to the inability to assess the quality of studies in the absence of their full texts. Furthermore, studies conducted among HIVinfected pregnant women were excluded as pregnancy by itself increased the risk of undernutrition, and nutritional assessment tools used for pregnant women are different from tools used for other adults [43]. Studies involving both HIV-infected and HIV-uninfected adults were excluded, unless data for HIV-infected adults were reported separately. Articles included only malnourished adults living with HIV were also not considered for this review as these lacked controls (i.e., well-nourished adults living with HIV).

\section{Measurement of outcome variables}

This systematic review focused on two outcomes. The first outcome was the effect of undernutrition on mortality among adults living with HIV. Undernutrition (underweight) was defined as a BMI of less than $18.5 \mathrm{~kg} / \mathrm{m}^{2}$. The severity of undernutrition was classified as severe $\left(\mathrm{BMI}<16 \mathrm{~kg} / \mathrm{m}^{2}\right)$, moderate (BMI $\left.16-16.99 \mathrm{~kg} / \mathrm{m}^{2}\right)$, and mild (BMI $17-18.48 \mathrm{~kg} / \mathrm{m}^{2}$ ) [44]. The second outcome was the effect of undernutrition on morbidities. Morbidity refers to the occurrence of any type of opportunistic infection, incidence of AIDS defined diseases, hospital admissions, and other types of illnesses related to HIVinfection as reported by each primary study. The pooled effects of undernutrition on mortality and morbidity were 


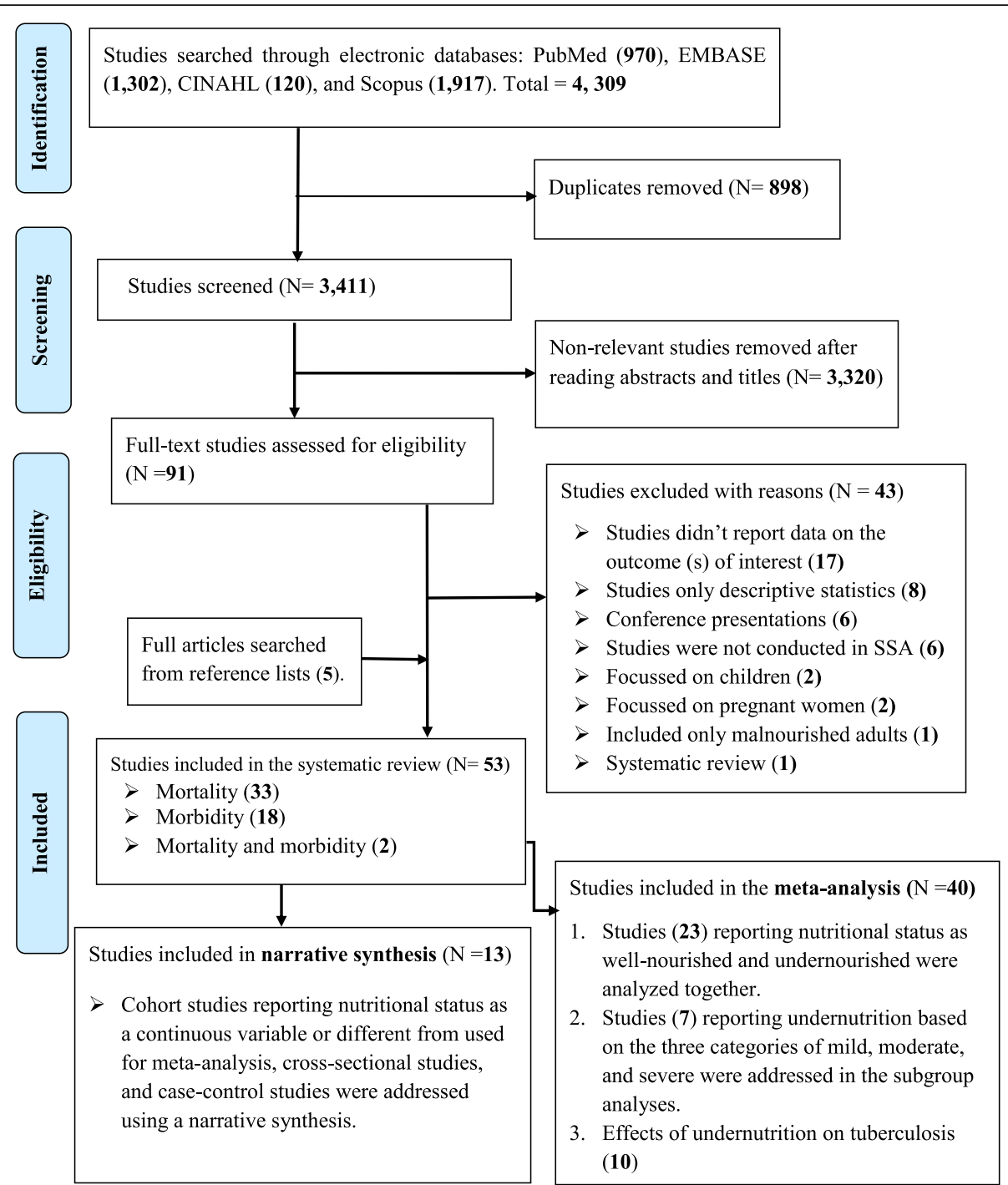

Fig. 1 Flow chart of study selection for a systematic review and meta-analysis of the effects of undernutrition on mortality and morbidity among adults living with HIV in SSA

determined using the (adjusted) hazard ratios reported from primary studies. For the meta-analysis, only cohort studies reporting the adjusted hazard ratios were included, as described previously.

\section{Quality appraisal}

The quality of included studies was appraised using the Newcastle-Ottawa scale (NOS) risk-of-bias assessment tool for cross-sectional, cohort, and case-control studies [45]. The NOS is validated for case-control and cohort studies with grading from zero to ten for cross-sectional, and zero to nine for case-control and cohort studies [46]. The three components of the tool are: selection, comparability, and outcome/exposure. The selection part of this tool was graded from zero to five stars for crosssectional studies, and zero to four stars for cohort and case-control studies. The comparability was graded from zero to two stars for all study designs. Lastly, the outcome/exposure was primarily related to the statistical analysis and cofounding handling mechanisms, which was graded from zero to three stars for all study designs.

During the quality appraisal, three (AA, DD, and DS) authors were involved, ensuring each study was appraised by two authors, with any disagreements between authors resolved through discussion. Finally, the quality score of each study was calculated as the sum of scores, thus ranging from zero to ten for cross-sectional studies, and zero to nine for cohort and case-control studies. Accordingly, articles receiving three or four stars in the selection, one or two stars in comparability, and two or three stars in outcomes were categorized as "good quality". Articles with two stars in the selection, one or two 
stars in comparability, and two or three stars in outcomes, were classified as "fair quality", whereas, a "poor quality" score was considered if the articles got zero or one-star(s) in the selection, or zero stars in comparability, or zero or one-star(s) in outcomes [47].

\section{Data extraction}

A standardized data extraction format was adopted and prepared based on the Joanna Briggs Institute (JBI) data extraction format [48]. The data extracted included the following: primary author, publication year, country/ countries where the study was conducted, study design, study/follow-up period, sample size, sex/ gender of participants, mortality rate/morbidity rate, and adjusted hazard ratio/ adjusted odds ratio with 95\% confidence intervals (CI). If further information or clarification was needed, the primary author of the original article was contacted through email. The article was excluded if, after at least two email attempts, the author did not respond. Before combining in a meta-analysis, the hazard ratios were transformed into a logarithmic scale as the hazard ratio was measured on a ratio (exponential) scale.

\section{Data synthesis}

A narrative synthesis approach was employed to present results, which were not included in the meta-analysis. A meta-analysis was performed using Stata ${ }^{\mathrm{Tm}}$ Version 16 statistical software to estimate effect sizes. Effect sizes were expressed as log-adjusted hazard ratios (AHR) with their 95\% CIs. In this meta-analysis, well-nourished adults living with HIV were considered as a reference (control) category. However, some primary studies reported AHR by considering undernourished adults living with HIV as a reference category, so to ensure consistency and uniformity, new AHRs with their 95\% CIs were calculated by taking the reciprocal of the reported AHRs [49]. Primary studies reporting the AHR based on the severity of undernutrition were included in our subgroup analysis because they reported nutritional status in three (mild, moderate, and severe) categories rather than two categories (undernutrition versus wellnourished). Studies reporting nutritional status (BMI) as a continuous variable were addressed in the narrative review.

\section{Heterogeneity, publication bias, and subgroup analyses} The presence of heterogeneity between included studies was assessed using Cochrane Q-test and $\mathrm{I}^{2}$ statistics. The $\mathrm{I}^{2}$ value can be interpreted as: 0 to $40 \%$ (might not be important); 30 to $60 \%$ (may represent moderate heterogeneity); 50 to $90 \%$ (may represent substantial heterogeneity); and 75 to $100 \%$ (considerable heterogeneity) [50]. In the case of significant heterogeneity, possible sources were investigated by performing univariate meta-regression analyses, and a random-effects metaanalysis model estimated the final effect size. Furthermore, to minimize random variations between primary studies, subgroup analyses were performed based on different variables (i.e., country where studies were conducted, degree of malnutrition, sample size, publication year, and quality score). We selected these variables because of the availability of data for these variables from most included studies. At last, the presence of publication bias was assessed using Egger's and Begg's tests at a $5 \%$ significance level [51].

\section{Results}

\section{Identification of studies}

A total of 4309 articles were identified from PubMed, EMBASE, Scopus, and CINAHL (Fig. 1). After the removal of 898 duplicates, 3411 studies remained and were screened for title and abstract. In the next step, 3320 articles were excluded based on titles and abstracts as these were not relevant for this review. The full text of 91 studies were downloaded and assessed based on the predefined inclusion criteria. An additional 43 full texts were excluded for the following reasons: 17 studies did not report data on the outcome(s) of interest [52-65], eight studies reported only descriptive results [66-76], six studies were conference presentations [77-82], six studies were not conducted in SSA [83-88], two studies focused on children (aged $<15$ years) $[89,90]$, two studies focused on pregnant women [91, 92], one study included only malnourished adults [93], and one was a review paper [94]. Five articles were added from the reference lists of included articles, leading to 53 included studies. Of these, 33 studies were conducted on mortality, 18 studies on morbidity, and two on both morbidity and both morbidity. Finally, 40 studies were available for the meta-analysis. Of these, 23 studies were used to estimate the pooled effects of undernutrition on mortality. Seven studies were included in the subgroup analysis to determine the effects of the severity of undernutrition (mild, moderate, and severe) on mortality. The remaining ten studies were used to estimate the pooled effects of undernutrition on tuberculosis.

\section{Description of included studies}

In this systematic review, a total of 367,680 adults living with HIV were included across included articles with more than three quarters (76.2\%) being females. Publication year of the included studies ranged from 2006 to 2019. The sample size of the included studies ranged from 71 in Kenya [95] to 68,378 in Tanzania [96]. Most were cohort studies $(n=47,88.7 \%)$. From the 32 studies that reported the number of deaths or proportion of mortality, the highest (38\%) mortality was reported from a study done in Kenya [95]; whereas the lowest (2\%) 
proportion mortality was reported from a study done in Cote d'Ivoire [25]. From the 19 included studies to assess the effects of undernutrition on morbidities, 14 studies were done on TB, two studies on anaemia, and one study each for intestinal parasite (IP), AIDS-defining disease, and OIs. Of the18 studies that reported the number of morbidities or proportion of morbidity, the highest proportion of morbidity (65\%) was recorded in a study conducted in Uganda [97]. Conversely, the lowest (2.4\%) proportion of morbidity was reported from a study conducted in South Africa [32] (Table 1). In this review, 13 SSA countries and six multi-country based studies were represented. In this regard, more than half $(55 \%)$ of the studies were conducted in Uganda $(n=8)$, Ethiopia $(n=13)$, and South Africa $(n=8)$ (Fig. 2).

\section{Quality appraisal results}

NOS quality scores ranged from five to nine for cohort studies and eight to ten for cross-sectional studies (Table 1 ). The mean quality score of the included studies was 7.34 (SD: 0.14). More than two-thirds (71.7\%) of the included studies had good quality. Fair or poor quality scores of the cohort studies were mainly due to the following reasons: lack of descriptions of loss to follow-up $(n=14,29.8 \%)$, shorter follow-up period $(n=30,63.8 \%)$, lack of description of the derivation of the exposed group ( $n=19,40.4 \%)$, and lack description of the derivation of the non-exposed group $(n=16,34 \%)$. All included studies controlled confounders through multivariable regression analysis. However, most of the cohort studies employed a single-arm study design (no control group). From 47 cohort studies included in our review, $14(29.8 \%)$ of the studies lacked a description of the loss to follow-up. Furthermore, six cohort studies reported that their loss to follow-up rate was more than $20 \%$. About $63.8 \%$ of the included cohort studies had a follow-up period of less than five years for mortality and/or less than two years for morbidities.

\section{Narrative analysis \\ The effects of undernutrition on mortality}

Five studies [95, 98, 102, 112, 124], which were not suitable for the meta-analysis, were included in the narrative analysis. A multi-county based retrospective cohort study involving 3749 adults living with HIV found that, as BMI increased in one unit, the hazard of death was reduced by $8 \%$ (AHR: $0.92,95 \%$ CI: $0.87,0.96$ ) [98]. A Kenyan retrospective cohort study followed 71 adults living with HIV with a median follow up time of 201 days found that as BMI increased in one unit, the hazard of death decreased by $18 \%$ (AHR: $0.82,95 \%$ CI: $0.68,0.99$ ) [95]. Another retrospective cohort study including 374 adults living with HIV from Uganda reported that adults living with $\mathrm{HIV}$ who had $\mathrm{BMI}<17.5 \mathrm{~kg} / \mathrm{m}^{2}$ were six-fold
(AHR: 6.11, 95\% CI: 2.3, 16.2) more likely to die as compared to well-nourished adults living with HIV. This study also documented that HIV positive adults, who had BMI between 17.5 and $18.49 \mathrm{~kg} / \mathrm{m}^{2}$, were four times (AHR: 4.5, 95\% CI: 1.54, 13.32) more likely to die than well-nourished adults living with [102]. Furthermore, a cross-sectional study involving 1507 participants conducted in Malawi reported that mild (AOR: AOR: 2.1, 95\% CI: 1.2, 3.8), moderate (AOR: 2.4, 95\% CI: 1.7, 6.3) and severe (AOR: 6, 95\% CI: 4.6, 12.7) undernutrition were significantly associated with mortality [112]. Lastly, a cross-sectional study involving 947 adults living with HIV reported from South Africa found that severe undernourishment (AOR: 3.71, 95\% CI: 1.89, 7.29) and BMI between 16 and $18.49 \mathrm{~kg} / \mathrm{m}^{2}$ (AOR: $2.35,95 \%$ CI: $1.3,4.26)$ were significantly associated with mortality in PLHIV [124].

\section{The effects of undernutrition on tuberculosis}

From the 15 studies assessed respecting the effects of undernutrition on tuberculosis (TB), five studies were not suitable for meta-analysis [115-119]. A Tanzanian prospective cohort study followed 67,685 adults living with HIV with a median follow-up time of 24 months indicated that patients living with HIV with a BMI $<17 \mathrm{~kg} /$ $\mathrm{m}^{2}$ (AHR: 1.96, 95\% CI: 1.83, 2.09), and BMI between 17 and $18.49 \mathrm{~kg} / \mathrm{m}^{2}$ (AHR: $1.69,95 \%$ CI: $1.58,1.8$ ) were at higher risk of TB [115]. An additional retrospective cohort study on 32,611 Nigerian adults living with HIV noted that within a median follow-up time of 29.2 months severely underweight $\left[\left(\mathrm{BMI}<16 \mathrm{~kg} / \mathrm{m}^{2}\right.\right.$ (AHR: 3.85, 95\% CI: 2.75, 5.38)], and underweight [(BMI: 16$18.49 \mathrm{~kg} / \mathrm{m}^{2}$ (AHR: 2.18, 95\% CI: 1.80, 2.65)] adults living with HIV had a higher risk to be diagnosed with TB [116]. Furthermore, a retrospective cohort study conducted among 254 adults living with HIV in Botswana documented that, as BMI increased in one unit, the risk of TB reduced by 19\% (AHR: 0.81, 95\% CI 0.66, 1.00: $P=0.05$ ) [118]. A case-control study undertaken with 357 adults living with HIV in Ethiopia reported that undernourished HIV positive adults had a higher risk of TB (AOR: 3.8, 95\% CI: 2.39, 6.08) [119]. Another prospective cohort study done among 473 adults living with HIV in Ghana found that undernutrition significantly increased the risk of TB (AOR: 2.51, 95\% CI: 1.15, 5.51) [117].

\section{The effects of undernutrition on other morbidities}

Five studies reported the effects of undernutrition on various morbidities in PLHIV [97, 120-123]. Two crosssectional studies from Uganda involved 400 participants [97], and Ethiopia involved 411participants [121] showed that undernutrition significantly increased the risk of anaemia among PLHIV with prevalence ratio (PR): 2.43 


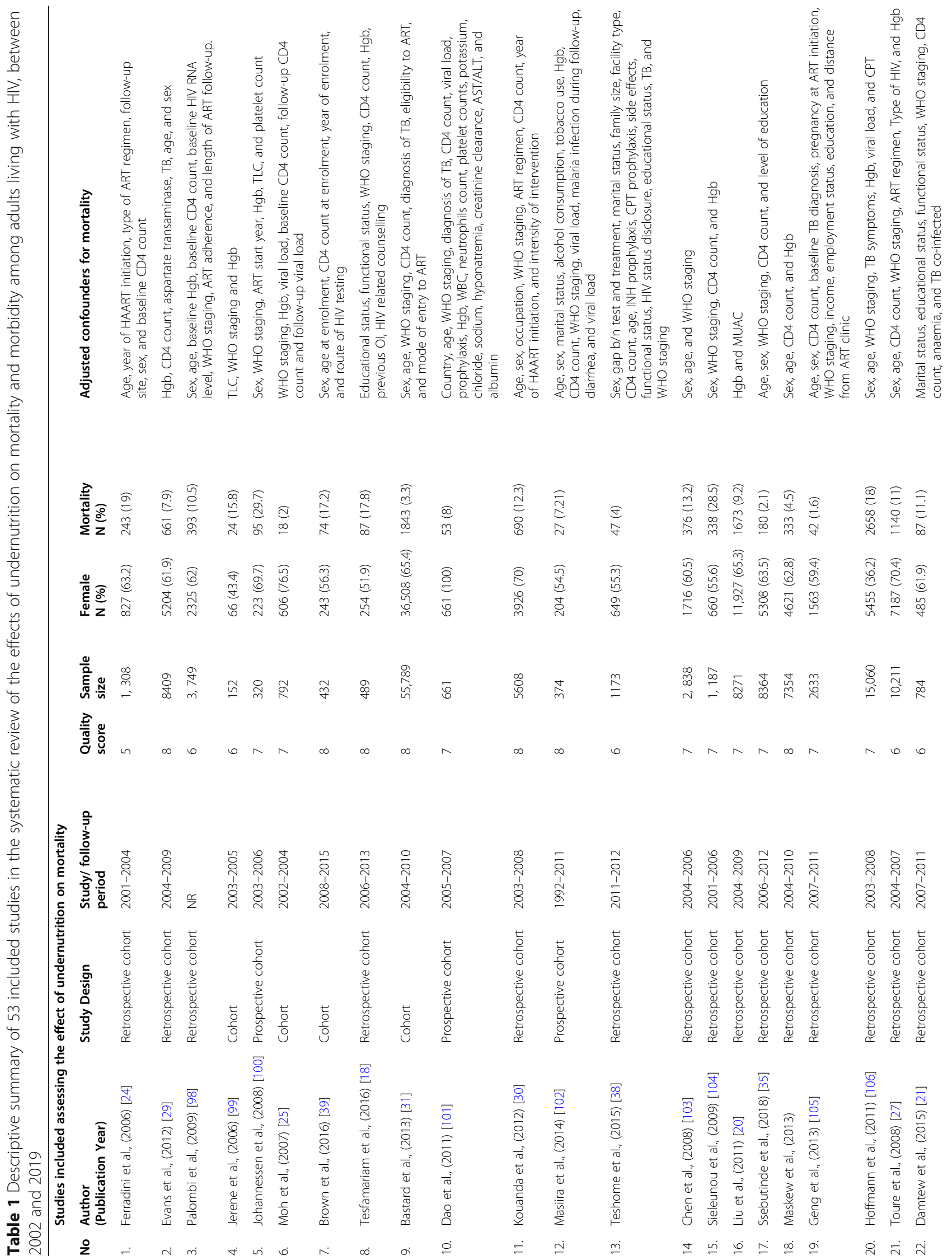



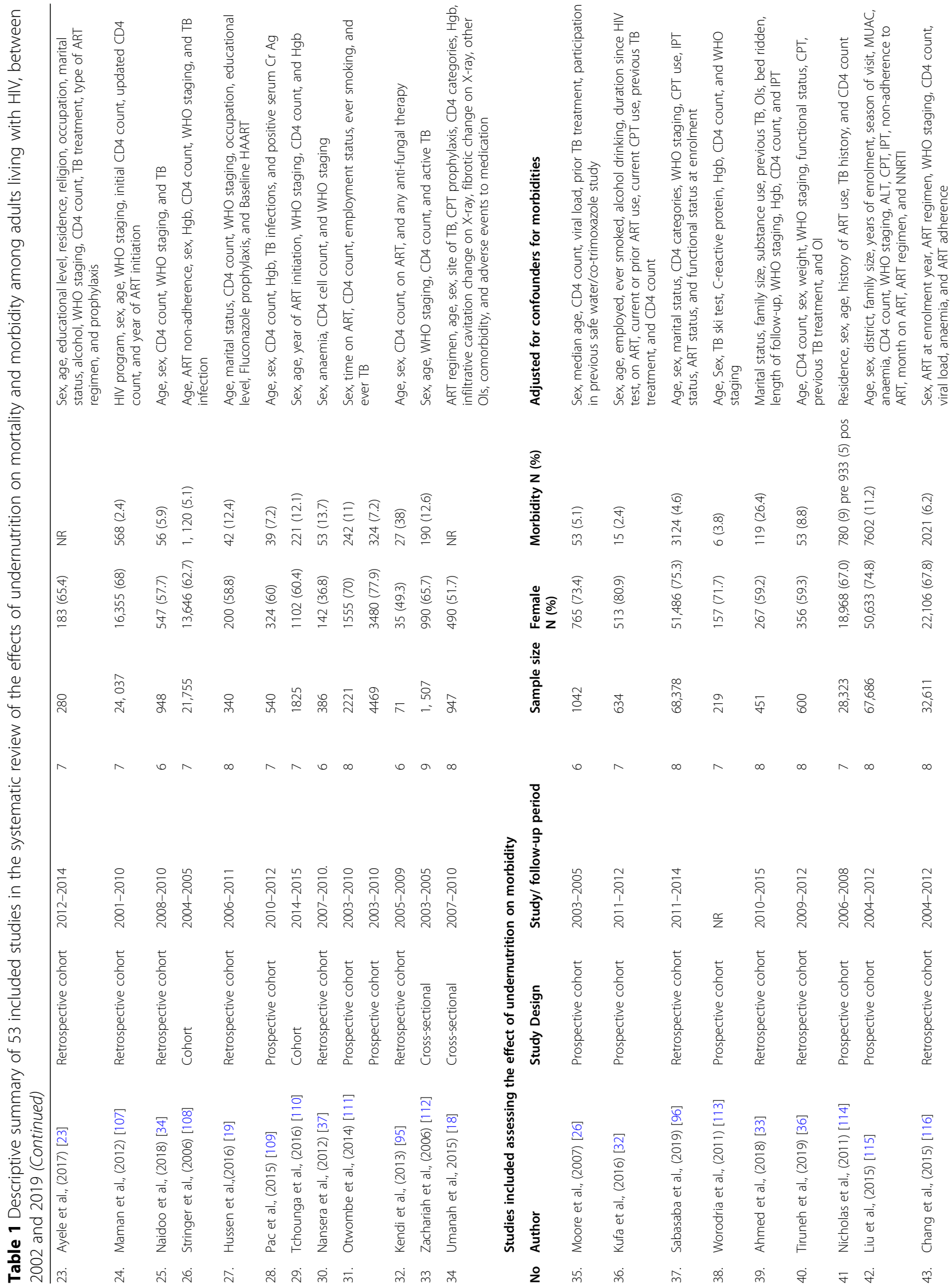


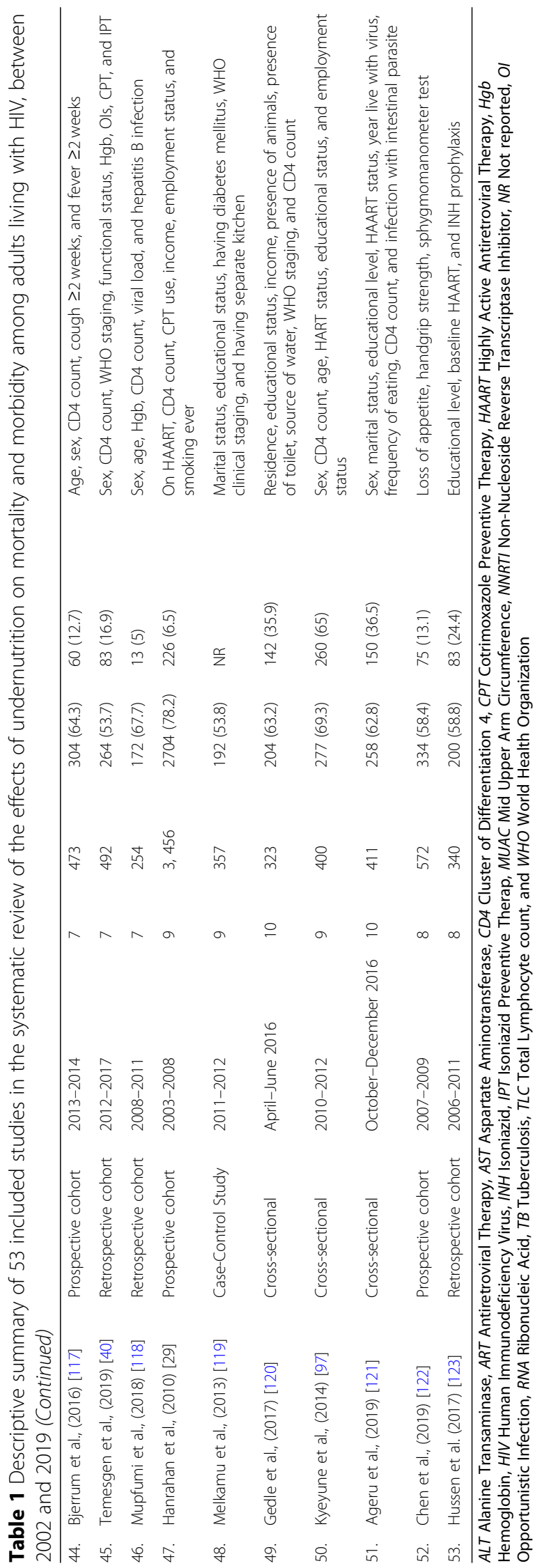




\section{Distribution of studies by country}

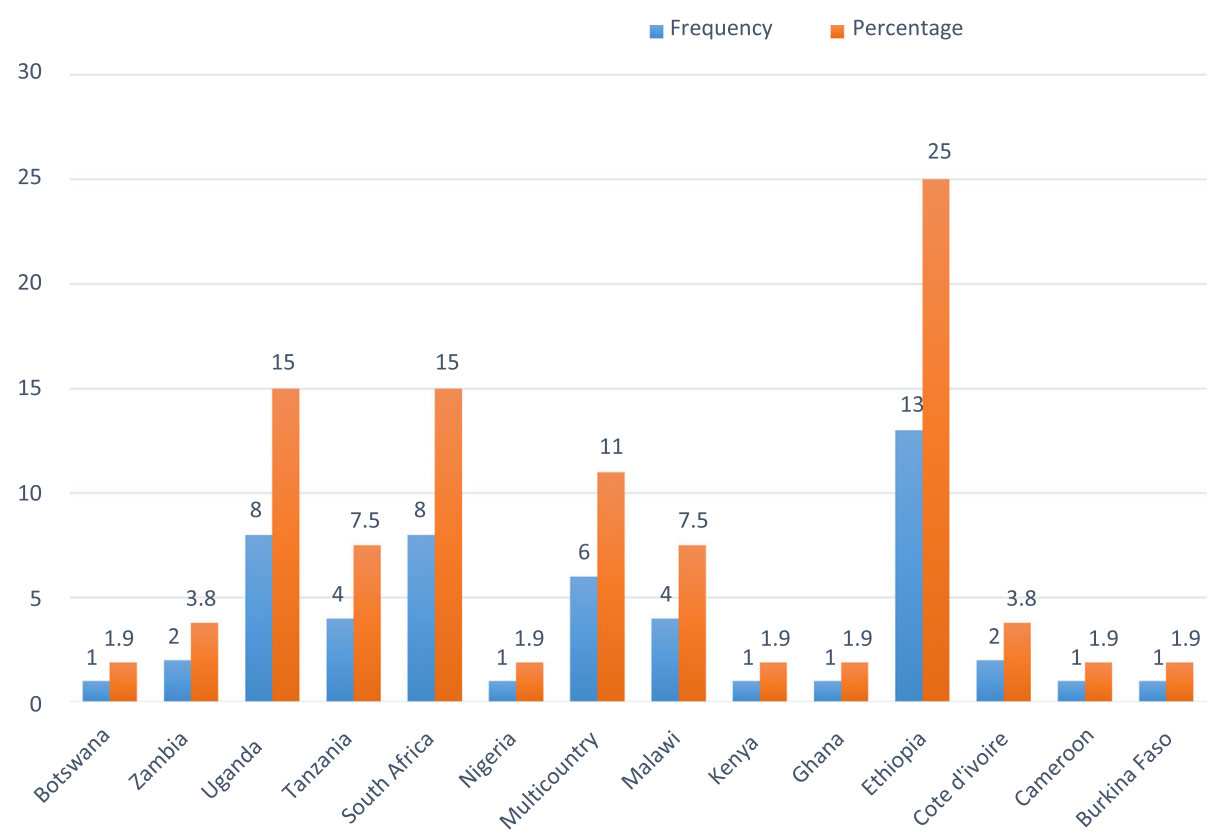

Fig. 2 The distribution of included studies across countries in SSA

(95\% CI: 1.01, 5.26) and AOR: 2.96 (95\% CI: 1.36, 6.39), respectively. A cross-sectional study conducted among 323 Ethiopian adults living with HIV reported that undernutrition was significantly associated with parasitic intestinal infections (AOR: 2.59, 95\% CI: 1.36, 4.95) [120]. Furthermore, a Zambian prospective cohort study involving 572 participants found that moderate wasting was significantly associated with AIDS-defining illnesses (AOR: 2.40, 95\% CI: 1.13, 5.10) [122]. At last, a retrospective cohort study conducted with 340 Ethiopian adults living with HIV showed that undernutrition was a significant risk of OIs (AHR: 2.27, 95\% CI: 1.4, 3.6) [123].

\section{Meta-analysis of the effects of undernutrition on mortality}

A total of 30 cohort studies were included in the metaanalysis. Of these, 23 studies reporting nutritional status as well-nourished (BMI between $18.5 \mathrm{~kg} / \mathrm{m}^{2}$ and $24.9 \mathrm{~kg} / \mathrm{m}^{2}$ ) and undernourished $\left(\mathrm{BMI}<18.5 \mathrm{~kg} / \mathrm{m}^{2}\right.$ ) were analyzed together. The remaining seven studies reporting undernutrition based on the three categories of mild, moderate, and severe were addressed in the subgroup analyses (Table 2). Of the 23 studies included in the meta-analysis, 17 studies showed that undernutrition has a significant effect on mortality in adults living with $\operatorname{HIV}[18,21,24,25,27-31,34$, $101,105,106,110,111]$. However, six studies reported that undernutrition has no significant effect on mortality in this population [19, 35, 37-39, 99]. Finally, the pooled AHR of
23 cohort studies involving 125,790 individuals showed that undernourished adults living with HIV were two-fold (AHR: 2.1, 95\% CI: 1.8, 2.4) more likely to die as compared to their well-nourished counterparts. The included studies exhibited substantial heterogeneity $\left(\mathrm{I}^{2}=66.4 \%\right.$ and Cochrane chi-squared test $p$-value $<0.001)$. As a result, a random-effects meta-analysis model was conducted to estimate the final pooled effect size (Fig. 3).

The possible sources of heterogeneity were explored using a meta-regression model considering the following continuous variables as moderators: publication year, sample size, and quality. None of these factors were significantly associated with heterogeneity. Publication bias was assessed using a funnel plot. Since the funnel plot had a symmetric inverted shape, it is unlikely that there is publication bias (Fig. 4). To confirm this finding, objective statistical tests (Begg's rank correlation and Egger's linear regression tests) were conducted, which confirmed that there was no publication bias among studies used to estimate the effect of undernutrition on mortality with $p=0.5$ and $p=0.8$.

\section{Subgroup analyses of effects of undernutrition on mortality}

The subgroup analyses of this review showed that severely undernourished adults living with HIV were at higher risk of death (AHR: 2.3, 95\% CI: 1.9, 2.8) as compared to mildly undernourished adults living with HIV 
Table 2 Subgroup analyses of the effect of undernutrition on mortality among adults living with HIV in SSA, between 2002 and 2019

\begin{tabular}{llllll}
\hline Variables & Subgroup & No of studies & Population $\mathbf{( N )}$ & AHR $(\mathbf{9 5} \% \mathbf{C l})$ & $\left(\mathbf{I}^{\mathbf{2}}(\mathbf{\%})\right.$ and Cochrane chi-squared test $\boldsymbol{p}$-value $)$ \\
\hline Severity of undernutrition & Severe & 6 & 66,110 & $2.3(1.9,2.8)$ & $(45.5,0.102)$ \\
& Moderate & 2 & 42,308 & $1.8(1.5,2.5)$ & $(52.3,0.145)$ \\
& Mild & 4 & 50,754 & $1.4(1.1,1.8)$ & $(60.9,0.053)$ \\
Geographical locations & Eastern Africa & 9 & 14,601 & $1.8(1.1,3.0)$ & $(75.9,<0.001)$ \\
& Western Africa & 3 & 16,611 & $2.5(1.9,3.3)$ & $(23,0.273)$ \\
& Sothern Africa & 8 & 36,303 & $2.1(1.8,2.3)$ & $(35.3,0.147)$ \\
Sample size & Multicounty & 3 & 58,275 & $2.4(1.3,4.4)$ & $(80,0.007)$ \\
& $\geq 5,470$ & 6 & 103,441 & $1.8(1.5,2.3)$ & $(79.3,<0.001)$ \\
Publication year & $<5,470$ & 17 & 22,349 & $2.3(1.9,2.9)$ & $(56.6,0.002)$ \\
Quality score & $\leq 2012$ & 9 & 45,657 & $2.3(1.9,2.7)$ & $(65.6,0.003)$ \\
& $>2012$ & 14 & 80,133 & $1.9(1.5,2.4)$ & $(68.2,<0.001)$ \\
& Good & 13 & 93,236 & $2.05(1.7,2.5)$ & $(73.3,<0.001)$ \\
\hline
\end{tabular}

\section{Effects of undernutrition $(B M l<18.5 \mathrm{Kg} / \mathrm{m} 2)$ on mortality}

Study

ID
$\%$

$\operatorname{AHR}(95 \% \mathrm{Cl}) \quad$ Weight

$2.92(2.04,4.17) 5.88$

$1.87(1.54,2.28) 7.76$

$2.70(0.92,7.95) 1.54$

$4.74(1.33,16.90) 1.16$

$1.65(1.00,2.72) 4.41$

$5.40(3.04,9.60) 3.78$

$1.64(1.32,2.03) 7.55$

$5.30(2.62,10.70) 2.94$

$2.66(2.23,3.18) 7.96$

$1.40(0.47,4.13) \quad 1.53$

$0.62(0.30,1.28) 2.84$

$3.08(1.61,5.89) \quad 3.27$

$1.90(1.67,2.16) 8.43$

$1.93(1.23,3.02) 4.89$

$2.20(1.18,4.10) \quad 3.45$

$2.21(0.89,5.50) 2.01$

$2.93(1.51,5.69) \quad 3.17$

$1.46(0.65,3.28) 2.41$

$2.06(1.24,3.41) 4.37$

$0.64(0.30,1.38) 2.61$

$1.74(1.06,2.85) 4.46$

$2.49(1.93,3.21) 7.10$

$1.80(1.32,2.45) 6.47$

$2.10(1.82,2.44) \quad 100.00$

Overall (I-squared $=66.4 \%, p=0.000)$

NOTE: Weights are from random effects analysis
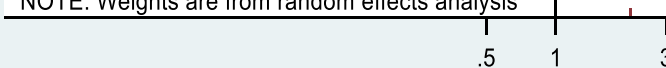

Fig. 3 Forest plot of the effects of undernutrition on mortality among adults living with HIV in SSA 


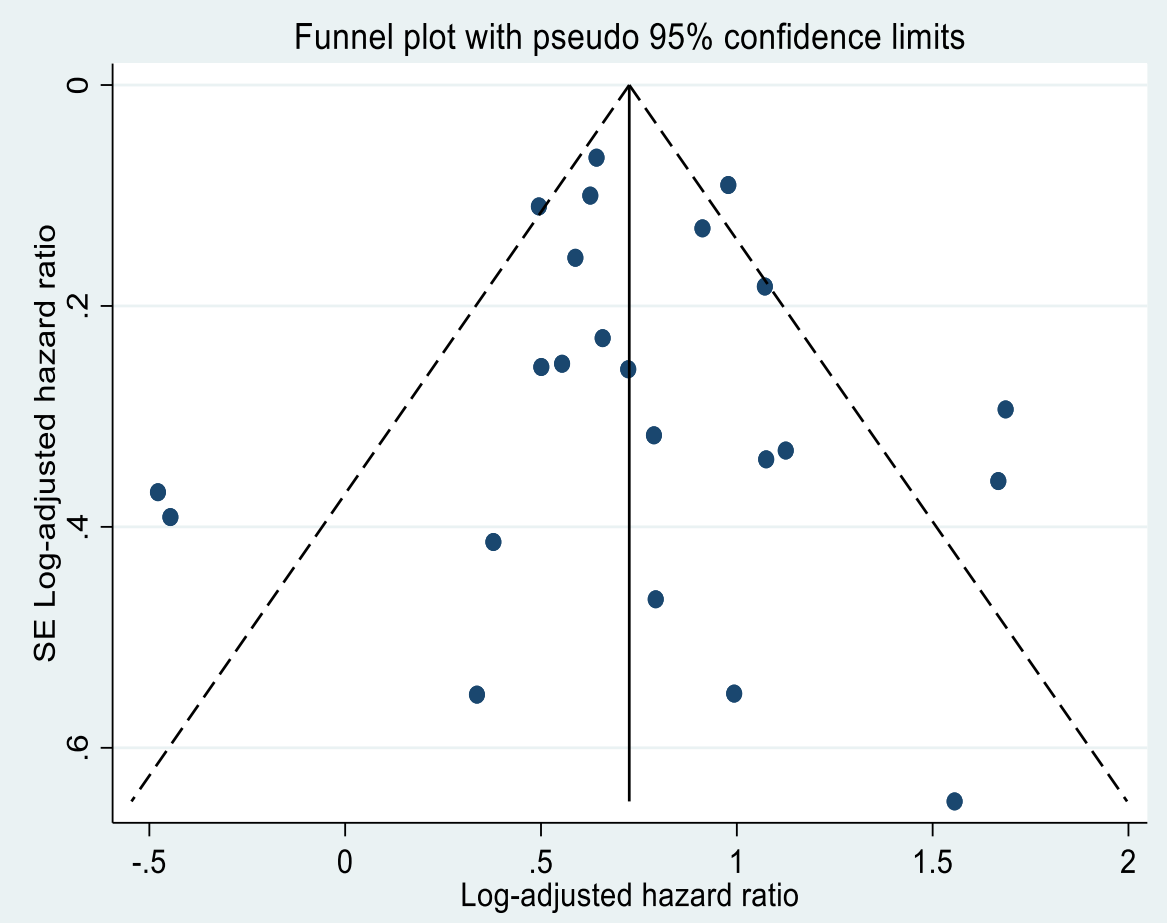

Fig. 4 Funnel plot of the effects of undernutrition on mortality among adults living with HIV in SSA

(using six studies) [20, 100, 104, 107-109]. However, the mortality rate between moderately undernourished (two studies) and mildly undernourished (four studies) adults living with HIV was not statistically significant [(AHR: 1.8, 95\% CI: 1.5, 2.5) [20, 107], and (AHR: 1.4, 95\% CI: $1.1,1.8)][20,30,103,107]$, respectively. Moreover, undernutrition on mortality is exacerbated in Western Africa as compared to other parts of SSA (AHR: 2.5, 95\% CI: $1.9,3.3)[25,27,30]$. The subgroup analyses also indicated that undernutrition has a more significant effect on mortality in studies published before 2012 (AHR: 2.3, 95\% CI: 1.9, 2.7) [24, 25, 27-30, 99, 101, 106] (Table 2).

\section{Meta-analysis of effects of undernutrition on TB}

A total of ten cohort studies involving 104,387 adults living with HIV were included in the meta-analysis. Of these ten studies, seven studies found that undernutrition has a significant effect on the occurrence of TB [26, 32, 33, 36, 96, 113, 114]. The remaining three studies found that undernutrition has no significant effect on the occurrence of $\mathrm{TB}[25,28,40]$. The final overall pooled effect found that undernutrition has a significant effect on the occurrence of TB among adults living with HIV (AHR: 2.1, 95\% CI: 1.6, 2.7) (Fig. 5). Significant heterogeneity $\left(\mathrm{I}^{2}=75.2 \%\right.$ and Cochrane chi-squared test $p$ value $<0.001)$ was observed; therefore, a random-effects meta-analysis model was computed to estimate the pooled effect. To investigate the possible sources of heterogeneity, a univariate random-effects meta-regression was done using continuous variables of publication year, sample size, quality as covariates [(Coefficient: -0.03 , p: 0.524), (Coefficient: -2.71 , p: 0.736) and (Coefficient: 0.31: 0.307 ) respectively]. Finally, publication bias between the included studies was also assessed using the funnel plot (Fig. 6) with confirmatory tests of publication bias done using Begg's rank correlation and Egger's linear regression tests. Accordingly, both test sets indicated there was no publication bias across included studies $(p=0.325$ and $p=0.767)$.

\section{Subgroup analyses of effects of undernutrition on TB}

Subgroup analyses were performed based on geographical locations, sample size, and year of publication. Our subgroup analyses indicated that undernutrition has a higher effect (AHR: 2.2, 95\% CI: 1.6: 2.9) on the occurrence of $\mathrm{TB}$ among adults living with HIV in studies done in Eastern Africa as compared to other parts of SSA. Interestingly, insignificant heterogeneity $\left(\mathrm{I}^{2}=51 \%\right.$, $p$-value $=0.069)$ was observed between studies conducted in Eastern Africa. The subgroup analysis based on publication year and sample size found no significant difference in undernutrition's effect on the occurrence of TB among adults living with HIV. However, a 


\section{Effects of undernutrition (BMI<18.5 Kg/m2) on Tuberculosis}

\begin{tabular}{|c|c|c|c|}
\hline Study & & & $\%$ \\
\hline ID & & $\operatorname{AHR}(95 \% \mathrm{Cl})$ & Weight \\
\hline Moore et al., (2007) & & $2.80(1.59,4.92)$ & 10.40 \\
\hline Kufa et al., (2016) & & $3.87(1.09,13.73)$ & 3.75 \\
\hline Sabasaba et al., (2019) & $\rightarrow$ & $1.80(1.50,2.10)$ & 17.37 \\
\hline Worodria et al., (2011) & & $5.85(1.24,27.46)$ & 2.69 \\
\hline Ahmed et al., (2018) & & $2.53(1.27,5.05)$ & 8.55 \\
\hline Tiruneh et al., (2019) & $\rightarrow$ & $3.13(1.77,5.53)$ & 10.33 \\
\hline Nicholas et al., (2011) & $\rightarrow$ & $2.78(2.38,3.22)$ & 17.60 \\
\hline Temesgen et al., (2019) & $\rightarrow$ & $1.30(0.80,2.10)$ & 11.81 \\
\hline Hanrahan et al., (2010) & $\rightarrow$ & $1.20(0.82,1.80)$ & 13.46 \\
\hline Moh et al., (2007) & & $0.71(0.21,2.35)$ & 4.05 \\
\hline Overall (I-squared $=75.2 \%, p=0.000)$ & & $2.07(1.57,2.72)$ & 100.00 \\
\hline NOTE: Weights are from random effects analysis & & & \\
\hline
\end{tabular}

Fig. 5 Forest plot of the effects of undernutrition on TB among adults living with HIV in SSA

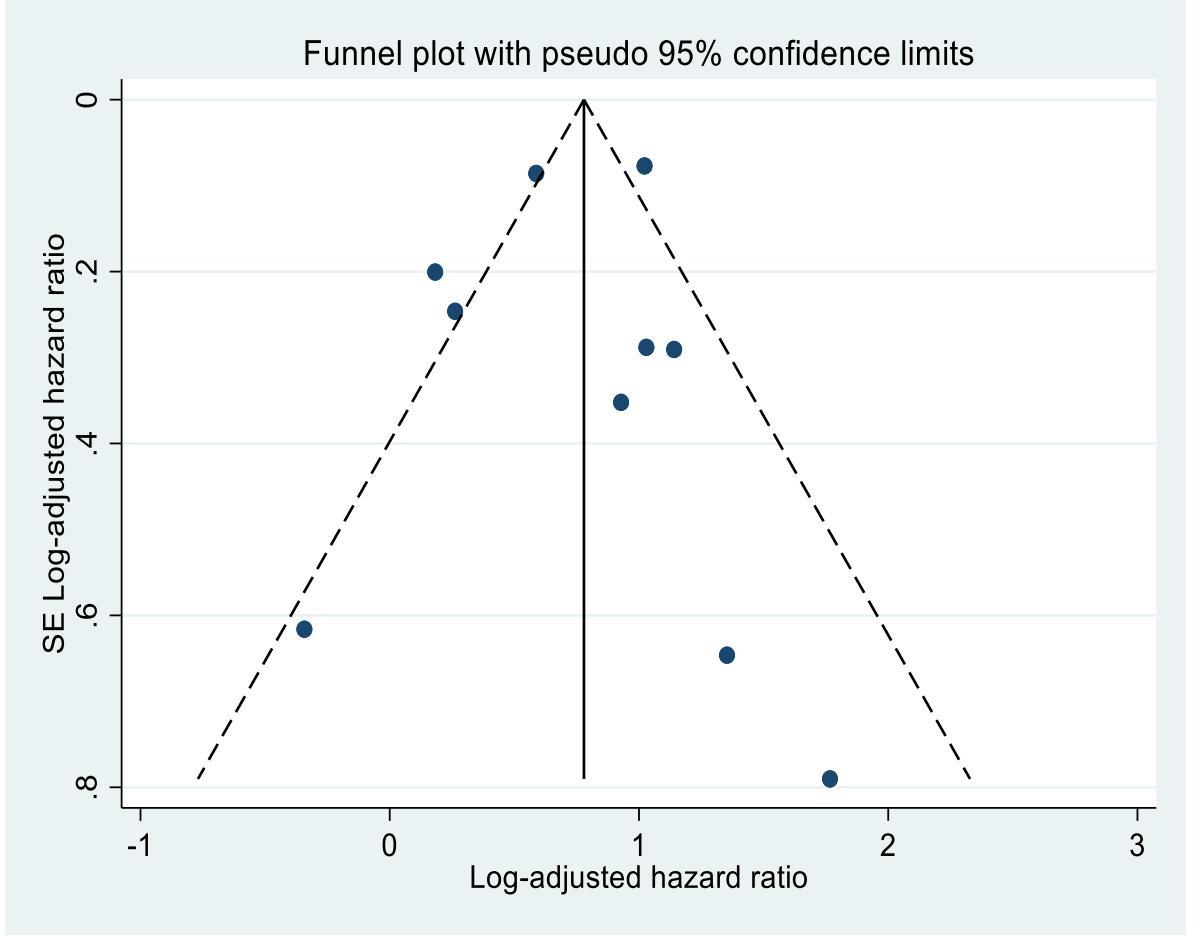

Fig. 6 Funnel plot of the effects of undernutrition on TB among adults living with HIV in SSA 
considerable heterogeneity difference was observed across these factors (Table 3).

\section{Discussion}

Despite encouraging recent scale-up of ART, nutritionrelated early mortality from HIV is a persistent concern in SSA. Therefore, this systematic review and metaanalysis aimed to estimate the pooled effects of undernutrition on mortality and morbidity among adults living with HIV in SSA. To the best of our knowledge, this review is the first of its kind. The findings of this review highlighted that undernutrition significantly increases the risk of mortality and morbidity in adults living with HIV in SSA, and that, as the degree of undernutrition became more severe, mortality rate also increased.

The overall pooled estimate of 23 cohort studies involving 125,790 adults living with HIV indicated that undernourished adults living with HIV were two times (AHR: 2.1, 95\% CI: 1.8, 2.4) more likely to die as compared to their well-nourished counterparts. Different mechanisms could explain the observed association between undernutrition and mortality. Undernutrition significantly impairs the immune response, which could increase the risk of developing and recurrence of OIs in the early phase of ART and ultimately contributing to early mortality. There is evidence that malnutrition adversely affects both innate and adaptive immunity systems, which are essential for defense against infections [125]. OIs are the leading cause of mortality among PLHIV, being responsible for more than 94\% of AIDSrelated deaths $[126,127]$.

Another mechanism explaining the effect of undernutrition on mortality could be due to its impact on the adherence level of ART. Different studies revealed that undernutrition is significantly associated with poor ART adherence levels [128, 129]. The effectiveness of HIV treatment depends on ART drug adherence. PLHIV are recommended to take their medications continuously and daily [130] as ART drug adherence is the proximal predictor of mortality [131, 132]. An additional possible explanation for the observed effect of undernutrition on mortality might be due to its impact on ART treatment failure [133]. PLHIV, who had a history of treatment failure or not taking their ART drug properly, are at higher risk of death as compared to those who had good treatment response or good adherence level to their ART drugs [134, 135].

This review found that, as the degree of undernutrition became more severe, mortality rate also increased. This dose-response relationship of undernutrition and mortality could result from the severity of malnourishment increasing the occurrence of OIs, which are the leading cause of mortality among PLHIV [16]. It is postulated that malnutrition and infection are interrelated in a vicious cycle [136]. Infections contribute to malnutrition through different means: increased metabolic demand, loss of appetite, and decreased absorption. On the contrary, malnutrition increases the risk of infections by causing immune deficiency, resulting in the persistence of malnutrition as the most common cause of immunodeficiency $[16,137]$.

The second outcome of this review demonstrated that undernutrition significantly increased the risk of developing morbidities among adults living with HIV. A meta-analysis of ten cohort studies involving 104,387 adults living with HIV showed that undernourished adults living with HIV were twice as likely to develop TB as compared to their well-nourished counterparts. Our finding is in line with a systematic review of cohort studies, which reported that a higher risk of TB was observed among adults with BMI $<18.5 \mathrm{~kg} / \mathrm{m}^{2}$ [138]. This finding might be due to malnutrition's weakening of the immune system and the concomitant increased risk of comorbidities including TB infections [139].

The relationship between malnutrition and $\mathrm{TB}$ has been well documented [140]. The bidirectional relationship is more accentuated among adults living with HIV, because HIV further weakened the immune system and increased the risk of TB. Evidence suggests that malnutrition increases the risk of disease progression from latent $\mathrm{TB}$ to active $\mathrm{TB}$ by weakening the immune system among adults living with HIV [141]. Besides, food insecurity may delay the health-seeking behavior, which results in late diagnosis and poor treatment adherence of TB [142]. This problem is more severe in SSA, where $68 \%$ of the PLHIV in 2018 lived [2, 4], and $23.2 \%$ of the world's food-insecure people in 2015 lived [143]. On the other hand, TB can cause loss of appetite, malabsorption, and increase metabolic demand [144].

Table 3 Subgroup analyses of the effect of undernutrition on TB among adults living with HIV in SSA, between 2002 and 2019

\begin{tabular}{llllll}
\hline Variables & Subgroup & No of studies & Population $(\mathbf{N})$ & AHR $(\mathbf{9 5 \%} \mathbf{C I})$ & $\left(\mathbf{I}^{\mathbf{2}} \mathbf{( \% )}\right.$ and Cochrane chi-squared test $\boldsymbol{p}$-value $)$ \\
\hline Geographical locations & Eastern Africa & 6 & 71,182 & $2.2(1.6,2.9)$ & $51,0.069$ \\
& Other countries & 4 & 33,205 & $1.8(0.9,3.5)$ & $84.9,<0.001$ \\
Sample size & $\geq 1,000$ & 4 & 101,199 & $2.02(1.4,2.9)$ & $87.8,<0.001$ \\
& $<1,000$ & 6 & 3,188 & $2.2(1.3,3.6)$ & $56.8,0.041$ \\
Publication year & $\leq 2012$ & 5 & 33,832 & $2.02(1.2,3.4)$ & $80.7,<0.001$ \\
& $>2012$ & 5 & 70,555 & $2.02(1.5,2.8)$ & $46.8,0.111$ \\
\hline
\end{tabular}


Finally, subgroup analyses confirmed that undernutrition appears to have a more deleterious effect on the occurrence of TB among adults living with HIV in Eastern Africa as compared to other parts of SSA. The possible explanation for this variance might be due to the economic differences across included countries. Likewise, the studies included in Eastern Africa were obtained from Ethiopia, Tanzania, and Uganda. According to the 2019 World Bank report, all three countries were classified as low-income [145]. Even though the clear association is not well known, poverty is widely recognized as the leading risk factor for TB [129]. Moreover, the accentuated effect of undernutrition on TB could be due to the clinical profile of the participants included in primary studies. As an example, more than half (54.6\%) of the participants involved in an Ethiopian study were classified as WHO clinical stage III and IV [33]. Furthermore, about $44.5 \%$ of the participants involved in a Tanzanian study were classified as WHO clinical stage III and IV [96]. The more advanced HIV/AIDS disease stage coincides with the increased occurrence and the recurrence of OIs, including TB [146]. According to the recent Ethiopian National ARV treatment guidelines, adults living with HIV presenting with pulmonary TB are classified as WHO stage III and with extra pulmonary TB are classified as WHO stage IV [147].

\section{What does this study add to what is known?}

Although different clinical trials showed nutritional interventions have no effect on mortality [16, 148, 149], the lancet HIV commentary paper strongly recommended that nutritional supplementations for patients on ART should be continued because it could increase body weight, hasten physical and functional recovery, and improve work capacity and quality of life [150]. Similarly, the WHO recommends that severely undernourished adults living with HIV should be treated with therapeutic foods. Moderately undernourished adults living with HIV can be treated with supplementary foods. Besides, nutritional assessments for PLHIV should be done regularly [151]. Although undernutrition is the proximal risk factor increasing mortality and morbidity among adults living with HIV [152], a comprehensive review estimating the effects of undernutrition on mortality and morbidity in this vulnerable population in SSA is lacking. Our results showed that undernutrition increased the risk of death and TB among adults living with HIV by two-fold. For policy makers and program planners, highly credible evidence obtained from systematic reviews and meta-analyses are vital. Therefore, findings from this review may be used to update the nutritional guidelines used for the management of PLHIV by different stakeholders, especially in limitedresource settings.

\section{Strengths and limitations}

There are a number of strengths with this review. An extensive search strategy was undertaken. Explicit inclusion and exclusion criteria regarding population, exposure, control, and outcomes were used. Three authors were involved in the quality assessment. A homogenous exposure category (BMI $<18.5 \mathrm{~kg} / \mathrm{m}^{2}$ ) was used rather than including studies that used different categories for the meta-analysis. Attempts were made to control the confounders by taking the AHR for the meta-analysis. Since the included studies exhibited considerable heterogeneity, advanced statistical analyses such as meta-regression were performed to identify possible heterogeneity sources. Most of the included studies used measured weight and height to calculate BMI from medical records rather than self-reported weight and height thereby avoiding recall biases.

Despite the above mentioned strengths, this review has some constraints that must be considered before interpreting results. This review included some studies with small sample sizes, potentially influencing findings. Our search limited to studies published in the English language, which may have resulted in the exclusion of a few essential studies. Many studies reported BMI in different categories making it difficult to include all studies in our meta-analysis. However, this variance has been addressed through subgroup analyses and qualitative analysis. Despite the use of AHR for our meta-analysis, most of the included primary studies used retrospective data. Thus, these studies did not include some important nutritional variables like socioeconomic status and dietary diversity. Furthermore, the actual effect of undernutrition on mortality could be confounded by undiagnosed acute diseases. This review included studies reported from 13 SSA countries and six multicounty based studies, which may yield underrepresentation of other SSA countries. Lastly, the majority of included studies used baseline BMI, but it changed continuously over time. Therefore, this result may not reflect the actual effects of malnutrition on mortality and morbidity.

\section{Conclusion}

This review found that undernutrition has significant effects on mortality and morbidity among adults living with HIV. As the degree of undernutrition became more severe, mortality rate also increased. Based on our findings, we recommended that nutritional assessment among adults living with HIV needs to be done regularly. Moreover, early screening of morbidities like TB among undernourished adults living with HIV is recommended. Furthermore, besides the management of malnutrition, comprehensive nutritional counselling to improve diet by consuming locally available needs to be reinforced at each visit for HIV care. Further studies are 
needed to examine the impact of nutritional interventions to improve nutritional status on mortality and morbidities among adults living with HIV. Finally, further follow-up studies considering malnutrition as exposure variable are needed to examine its actual effects on mortality and morbidities.

\section{Supplementary Information}

The online version contains supplementary material available at https://doi. org/10.1186/s12879-020-05706-z

Additional file 1. PRISMA 2009 Checklist.

Additional file 2. 1. PubMed search history. 2. EMBASE search history (Elsevier). 3. Scopus search history. 4. Search from CINHAL.

\section{Abbreviations}

AHR: Adjusted hazard ratio; AIDS: Acquired Immunodeficiency syndrome; ART: Antiretroviral therapy; BMI: Body mass index; Cl: Confidence interval; HAART: Highly active antiretroviral treatment; HIV: Human immunodeficiency virus; LMICs: Low and middle-income countries; NOS: Newcastle-Ottawa scale; Ols: Opportunistic infections; PLHIV: People living with human immunodeficiency virus; SSA: Sub-Saharan Africa; TB: Tuberculosis; WHO: World health Organization

\section{Acknowledgments}

The authors want to extend their special thanks to the librarians working at the University of Technology Sydney Library for their kindness and generous support during literature searching. The authors also extend their heartfelt thanks to the authors of primary papers included in this review.

\section{Authors' contributions}

AA: Conception of research protocol, study design, literature review, quality assessment, data extraction, data analysis, interpretation and drafting the manuscript. DD and DS: Conception of research protocol, study design, quality assessment, reviewing and editing the manuscript. PP: Interpretation of the data, reviewing, and editing the manuscript. All authors have read and approved the manuscript.

\section{Funding}

Funding was not available for this study.

\section{Availability of data and materials}

The data sets used and/or analyzed for this review are available from the corresponding author on reasonable request.

\section{Ethics approval and consent to participate}

Not applicable.

\section{Consent for publication}

Not applicable.

\section{Competing interests}

The authors have declared that they have no competing interests.

\section{Author details}

${ }^{1}$ College of Health Science, Debre Markos University, Debre Markos, Ethiopia. ${ }^{2}$ School of Public Health, Faculty of Health, University of Technology Sydney, Ultimo, NSW, Australia. ${ }^{3}$ School of Public Health and Social Work, Faculty of Health, Queensland University of Technology, Kelvin Grove, NSW, Australia. ${ }^{4}$ College of Nursing, University of Saskatchewan, Saskatoon, Canada. ${ }^{5}$ School of Life Sciences and Bioengineering, Nelson Mandela African Institute of Science and Technology, Arusha, Tanzania.
Received: 28 February 2020 Accepted: 11 December 2020

Published online: 04 January 2021

\section{References}

1. Kharsany AB, Karim QA. HIV infection and AIDS in sub-Saharan Africa: current status, challenges and opportunities. Open AIDS J. 2016;10:3448.

2. World Health Organization: HIV/Aids factsheets available at https://www. who.int/news-room/fact-sheets/detail/hiv-aids accessed date 03 Jan 2020.

3. UNAIDS: Global HIV \& AIDS statistics - 2019 fact sheet available at https:// www.unaids.org/en/resources/fact-sheet accessed date 03 Jan 2020.

4. UNAIDS: FACT SHEET-WORLD AIDS DAY 2019 available at https://www unaids.org/sites/default/files/media_asset/UNAIDS_FactSheet_en.pdf accessed date 03 Jan 2020.

5. Centres for Disease Control and Prevention (CDC): HIV Treatment available at https://www.cdc.gov/hiv/basics/livingwithhiv/treatment.html accessed date 04 Jan 2020

6. World Health Organization: Antiretroviral therapy (ART) coverage among all age groups available at https://www.who.int/gho/hiv/epidemic_response/ ART/en/ accessed date 04 Jan 2020.

7. Maleta K. Undernutrition. Malawi Med J. 2006;18(4):189-205.

8. World Health Organization: Nutritional care and support for people living with HIV/AIDS: a training course available at https://apps.who.int/iris/ bitstream/handle/10665/44384/9789241591898_eng_Participant. pdf? sequence $=3$. accessed 15 Feb 2020; 2009.

9. Edmonds A, Yotebieng M, Lusiama J, Matumona Y, Kitetele F, Napravnik S, Cole SR, Van Rie A, Behets F. The effect of highly active antiretroviral therapy on the survival of HIV-infected children in a resource-deprived setting: a cohort study. PLoS Med. 2011;8(6):e1001044.

10. Duggal S, Chugh TD, Duggal AK. HIV and malnutrition: effects on immune system. Clin Dev Immunol. 2012;2012

11. Trehan I, O'Hare BA, Phiri A, Heikens GT. Challenges in the management of HIV-infected malnourished children in sub-Saharan Africa. AIDS Res Treat. 2012;2012:790786

12. Food and Agriculture Organization of the United Nations: The state of food security and nutrition in the world available at http://www.fao.org/3/ca5162 en/ca5162en.pdf accessed date 04 Jan 2019. In Rome; 2019.

13. Thimmapuram R, Lanka S, Esswein A, Dall L. Correlation of nutrition with immune status in human immunodeficiency virus outpatients. Mo Med. 2019;116(4):336-9.

14. Weiser SD, Young SL, Cohen CR, Kushel MB, Tsai AC, Tien PC, Hatcher AM, Frongillo EA, Bangsberg DR. Conceptual framework for understanding the bidirectional links between food insecurity and HIV/AIDS. Am J Clin Nutr. 2011;94(6):1729s-39s.

15. Kosmiski L. Energy expenditure in HIV infection. Am J Clin Nutr. 2011;94(6): 1677s-82s.

16. França T, Ishikawa L, Zorzella-Pezavento S, Chiuso-Minicucci F, da Cunha M, Sartori A. Impact of malnutrition on immunity and infection. J Venomous Anim Toxins Incl Trop Dis. 2009;15(3):374-90.

17. Enwonwu CO. Complex interactions between malnutrition, infection and immunity: relevance to HIV/AIDS infection. Nig J Clin Biomed Res. 2006;1(1): 6-14

18. Tesfamariam K, Baraki N, Kedir H. Pre-ART nutritional status and its association with mortality in adult patients enrolled on ART at fiche Hospital in North Shoa, Oromia region, Ethiopia: a retrospective cohort study. BMC Res Notes. 2016:9(1):512.

19. Hussen S, Belachew T, Hussien N. Nutritional status and its effect on treatment outcome among HIV infected clients receiving HAART in Ethiopia: a cohort study. AIDS Res Ther. 2016;13:32.

20. Liu E, Spiegelman D, Semu H, Hawkins C, Chalamilla G, Aveika A, Nyamsangia S, Mehta S, Mtasiwa D, Fawzi W. Nutritional status and mortality among HIV-infected patients receiving antiretroviral therapy in Tanzania. J Infect Dis. 2011:204(2):282-90.

21. Damtew B, Mengistie B, Alemayehu T. Survival and determinants of mortality in adult HIV/aids patients initiating antiretroviral therapy in Somali region, Eastern Ethiopia. Pan Afr Med J. 2015;22:138.

22. Hu W, Jiang H, Chen W, He S-H, Deng B, Wang W-Y, Wang Y, Lu CD, Klassen $\mathrm{K}$, Zeng J. Malnutrition in hospitalized people living with HIV/AIDS: evidence from a cross-sectional study from Chengdu, China. Asia Pac J Clin Nutr. 2011;20(4):544. 
23. Ayele $T$, Jarso $H$, Mamo G. Clinical outcomes of tenofovir versus zidovudinebased regimens among people living with hiv/aids: a two years retrospective cohort study. Open AIDS J. 2017;11:1-11.

24. Ferradini $L$, Jeannin A, Pinoges L, Izopet J, Odhiambo D, Mankhambo L, Karungi G, Szumilin E, Balandine S, Fedida G, et al. Scaling up of highly active antiretroviral therapy in a rural district of Malawi: An effectiveness assessment. Lancet. 2006;367(9519):1335-42.

25. Moh R, Danel C, Messou E, Ouassa T, Gabillard D, Anzian A, Abo Y, Salamon R, Bissagnene E, Seyler $C$, et al. Incidence and determinants of mortality and morbidity following early antiretroviral therapy initiation in HIV-infected adults in West Africa. AIDS. 2007;21(18):2483-91.

26. Moore D, Liechty C, Ekwaru P, Were W, Mwima G, Solberg P, Rutherford G, Mermin J. Prevalence, incidence and mortality associated with tuberculosis in HIV-infected patients initiating antiretroviral therapy in rural Uganda. AIDS. 2007;21(6):713-9.

27. Toure S, Kouadio B, Seyler C, Traore M, Dakoury-Dogbo N, Duvignac J, Diakite N, Karcher S, Grundmann C, Marlink R, et al. Rapid scaling-up of antiretroviral therapy in 10,000 adults in Côte d'Ivoire: 2-year outcomes and determinants. AIDS. 2008:22(7):873-82.

28. Hanrahan CF, Golub JE, Mohapi L, Tshabangu N, Modisenyane T, Chaisson RE, Gray GE, Mclntyre JA, Martinson NA. Body mass index and risk of tuberculosis and death. AIDS. 2010;24(10):1501-8.

29. Evans D, Maskew M, Sanne I. Increased risk of mortality and loss to followup among HIVpositive patients with oropharyngeal candidiasis and malnutrition before antiretroviral therapy initiation: a retrospective analysis from a large urban cohort in Johannesburg, South Africa. Oral Surg Oral Med Oral Pathol Oral Radiol. 2012;113(3):362-72.

30. Kouanda S, Meda IB, Nikiema L, Tiendrebeogo S, Doulougou B, Kaboré I, Sanou MJ, Greenwell F, Soudré R, Sondo B. Determinants and causes of mortality in HIV-infected patients receiving antiretroviral therapy in Burkina Faso: a five-year retrospective cohort study. AIDS Care. 2012; 24(4):478-90

31. Bastard M, Nicolay N, Szumilin E, Balkan S, Poulet E, Pujades-Rodriguez M. Adults receiving HIV care before the start of antiretroviral therapy in subSaharan Africa: patient outcomes and associated risk factors. J Acquir Immune Defic Syndr. 2013;64(5):455-63.

32. Kufa T, Chihota V, Mngomezulu V, Charalambous S, Verver S, Churchyard G, Borgdorff $M$. The incidence of tuberculosis among hiv-positive individuals with high CD4 counts: Implications for policy. BMC Infect Dis. 2016;16(1).

33. Ahmed A, Mekonnen D, Shiferaw AM, Belayneh F, Yenit MK. Incidence and determinants of tuberculosis infection among adult patients with HIV attending HIV care in north-east Ethiopia: A retrospective cohort study. BMJ Open. 2018;8(2).

34. Naidoo K, Yende-Zuma N, Augustine S. A retrospective cohort study of body mass index and survival in HIV infected patients with and without TB co-infection. Infect Dis Poverty. 2018;7(1).

35. Ssebutinde P, Kyamwanga IT, Turyakira E, Asiimwe S, Bajunirwe F. Effect of age at initiation of antiretroviral therapy on treatment outcomes; a retrospective cohort study at a large HIV clinic in southwestern Uganda. PLoS One. 2018;13(8):e0201898.

36. Tiruneh G, Getahun A, Adeba E. Assessing the impact of isoniazid preventive therapy (IPT) on tuberculosis incidence and predictors of tuberculosis among adult patients enrolled on ART in Nekemte town Western Ethiopia: a retrospective cohort study. Interdiscip Perspect Infect Dis. 2019:2019:1413427

37. Nansera D, Bajunirwe F, Elyanu P, Asiimwe C, Amanyire G, Graziano FM. Mortality and loss to follow-up among tuberculosis and HIV co-infected patients in rural southwestern Uganda. Int J Tuberc Lung Dis. 2012;16(10): 1371-6

38. Teshome W, Moges M, Mekonnen E, Endrias M, Ayele $S$, Misganaw T, Shiferaw M, Tesema T. Do loss to follow-up and death rates from ART care vary across primary health care facilities and hospitals in South Ethiopia? A retrospective follow-up study. HIV/AIDS Res Palliat Care. 2015;7:167-74

39. Brown JP, Ngwira B, Tafatatha T, Crampin AC, French N, Koole O. Determinants of time to antiretroviral treatment initiation and subsequent mortality on treatment in a cohort in rural northern Malawi. AIDS Res Ther 2016;13(1).

40. Temesgen B, Kibret GD, Alamirew NM, Melkamu MW, Hibstie YT, Petrucka P, Alebel A. Incidence and predictors of tuberculosis among HIV-positive adults on antiretroviral therapy at Debre Markos referral hospital, Northwest Ethiopia: a retrospective record review. BMC Public Health. 2019;19(1):1566.
41. Liberati A, Altman DG, Tetzlaff J, Mulrow C, Gotzsche PC, loannidis JP, Clarke M, Devereaux PJ, Kleijnen J, Moher D. The PRISMA statement for reporting systematic reviews and meta-analyses of studies that evaluate health care interventions: explanation and elaboration. J Clin Epidemiol. 2009;62(10):e134.

42. World Health Organization. Scaling up antiretroviral therapy in resourcelimited settings. Geneva: World Health Organization; 2002. available at https://apps.who.int/iris/bitstream/handle/10665/42514/9241545674.pdf, accessed 16 Feburary 2020.

43. Ververs MT, Antierens A, Sackl A, Staderini N, Captier V. Which anthropometric indicators identify a pregnant woman as acutely malnourished and predict adverse birth outcomes in the humanitarian context? PLoS Curr. 2013;5.

44. Purnell JQ: Definitions, Classification, and Epidemiology of Obesity. In: Endotext [Internet]. edn.: MDText. com, Inc.; 2018.

45. Peterson J, Welch V, Losos M, Tugwell P. The Newcastle-Ottawa scale (NOS) for assessing the quality of nonrandomised studies in meta-analyses. Ottawa: Ottawa Hospital Research Institute; 2011.

46. Luchini C, Stubbs B, Solmi M, Veronese N. Assessing the quality of studies in meta-analyses: advantages and limitations of the Newcastle Ottawa scale. World J Metaanal. 2017;5(4):80-4.

47. Penson D, Krishnaswami S, Jules A: Newcastle-Ottawa Quality Assessment Form for Cohort Studies. 2012. In.; 2018.

48. Peters M, Godfrey-smith P, Mcinerney P: Guidance for the conduct of JBI scoping reviews Joanna Briggs Institute Reviewer's Manual South Australia: Joanna Briggs Institute 2019.

49. Kleinbaum D, Klein M, Pryor E. Logistic Regression A Self-Learning Text. Berlin: Springer; 2010.

50. Cumpston M, Li T, Page MJ, Chandler J, Welch VA, Higgins JP, Thomas J. Updated guidance for trusted systematic reviews: a new edition of the cochrane handbook for systematic reviews of interventions. Cochrane Database Syst Rev. 2019;3(10).

51. Lin L, Chu H. Quantifying publication bias in meta-analysis. Biometrics. 2018; 74(3):785-94.

52. Hosseinipour MC, Kumwenda JJ, Weigel R, Brown LB, Mzinganjira D, Mhango B, Eron JJ, Phiri S, van Oosterhout JJ. Second-line treatment in the Malawi antiretroviral programme: high early mortality, but good outcomes in survivors, despite extensive drug resistance at baseline. HIV Med. 2010; $11(8): 510-8$

53. Russell EC, Charalambous S, Pemba L, Churchyard GJ, Grant AD, Fielding K. Low haemoglobin predicts early mortality among adults starting antiretroviral therapy in an HIV care programme in South Africa: a cohort study. BMC Public Health. 2010;10:433.

54. Koethe JR, Blevins M, Nyirenda CK, Kabagambe EK, Chiasera JM, Shepherd BE, Zulu I, Heimburger DC. Serum phosphate predicts early mortality among underweight adults starting ART in Zambia: a novel context for refeeding syndrome? J Nutr Metab. 2013;2013.

55. Molfino L, Kumar AM, Isaakidis P, Van den Bergh R, Khogali M, Hinderaker SG, Magaia A, Lobo S, Edwards CG, Walter J. High attrition among HIVinfected patients with advanced disease treated in an intermediary referral center in Maputo, Mozambique. Glob Health Action. 2014:7:23758.

56. Bezabhe WM, Bereznicki LR, Chalmers L, Gee P, Kassie DM, Bimirew MA, Peterson GM. Adverse dug reactions and clinical outcomes in patients initiated on antiretroviral therapy: a prospective cohort study from Ethiopia. Drug Saf. 2015:38(7):629-39.

57. Boullé C, Kouanfack C, Laborde-Balen G, Boyer S, Aghokeng AF, Carrieri MP, Kazé S, Dontsop M, Mben JM, Koulla-Shiro S, et al. Gender differences in adherence and response to antiretroviral treatment in the Stratall trial in rural district hospitals in Cameroon. J Acquir Immune Defic Syndr. 2015; 69(3):355-64.

58. Bucciardini R, Fragola $V$, Abegaz T, Lucattini S, Halifom A, Tadesse E, Berhe M, Pugliese K, Binelli A, De Castro $P$, et al. Retention in care of adult HIV patients initiating antiretroviral therapy in Tigray, Ethiopia: A prospective observational cohort study. PLoS One. 2015;10(9).

59. Herce ME, Kalanga N, Wroe EB, Keck JW, Chingoli F, Tengatenga L, Gopal S, Phiri A, Mailosi B, Bazile J, et al. Excellent clinical outcomes and retention in care for adults with HIV-associated Kaposi sarcoma treated with systemic chemotherapy and integrated antiretroviral therapy in rural Malawi. J Int AIDS Soc. 2015;18:19929.

60. Stete K, Glass TR, van Dam GJ, Ntamatungiro A, Letang E, de Dood CJ, Corstjens PLAM, Ndege R, Mapesi H, Kern W, et al. Effect of schistosomiasis 
on the outcome of patients infected with HIV-1 starting antiretroviral therapy in rural Tanzania. PLoS Negl Trop Dis. 2018;12(10).

61. Van Der Sande MAB, Van Der Loeff MF, Aveika AA, Sabally S, Togun T, Sarge-Njie R, Alabi AS, Jaye A, Corrah T, Whittle HC. Body mass index at time of HIV diagnosis: a strong and independent predictor of survival. J Acquir Immune Defic Syndr. 2004;37(2):1288-94.

62. Nakanjako D, Mayanja-Kizza H, Ouma J, Wanyenze R, Mwesigire D, Namale A, Ssempiira J, Senkusu J, Colebunders R, Kamya MR. Tuberculosis and human immunodeficiency virus co-infections and their predictors at a hospital-based HIV/AIDS clinic in Uganda. Intl J Tuberc Lung Dis. 2010; 14(12):1621-8.

63. Van Rie A, Westreich D, Sanne I. Tuberculosis in patients receiving antiretroviral treatment: incidence, risk factors, and prevention strategies. J Acquir Immune Defic Syndr. 2011;56(4):349-55.

64. Hoffmann CJ, Chaisson RE, Martinson NA. Cotrimoxazole prophylaxis and tuberculosis risk among people living with HIV. PLoS One. 2014;9(1).

65. Lawn SD, Badri M, Wood R. Tuberculosis among HIV-infected patients receiving HAART: long term incidence and risk factors in a south African cohort. Aids. 2005;19(18):2109-16

66. Holmes CB, Wood R, Badri M, Zilber S, Wang B, Maartens G, Zheng H, Lu Z, Freedberg KA, Losina E. CD4 decline and incidence of opportunistic infections in Cape Town, South Africa: implications for prophylaxis and treatment. J Acquir Immune Defic Syndr. 2006;42(4):464-9.

67. Kasonka L, Makasa M, Marshall T, Chisenga M, Sinkala M, Chintu C, Kaseba C, Kasolo F, Gitau R, Tomkins A et al: Risk factors for subclinical mastitis among HIV-infected and uninfected women in Lusaka, Zambia. Paediatr Perinat Epidemiol 2006, 20(5):379-391.

68. Donovan C, Massingue J. Illness, death, and macronutrients: adequacy of rural Mozambican household production of macronutrients in the face of HIV/AIDS. Food Nutr Bull. 2007:28(2 Suppl):S331-8.

69. Estopinal CB, van Dijk JH, Sitali S, Stewart H, Davidson MA, Spurrier J, Vermund $\mathrm{SH}$. Availability of volunteer-led home-based care system and baseline factors as predictors of clinical outcomes in HIV-infected patients in rural Zambia. PLoS One. 2012;7(12):e49564.

70. Henostroza G, Harris JB, Chitambi R, Siyambango M, Turnbull ER, Maggard KR, Krüüner A, Kapata N, Reid SE. High prevalence of tuberculosis in newly enrolled HIV patients in Zambia: need for enhanced screening approach. Int J Tuberc Lung Dis. 2016;20(8):1033-9.

71. Sørensen A, Jespersen S, Katzenstein TL, Medina C, da Silva TD, Correira FG, Hviid CJ, Laursen AL, Wejse C. Clinical presentation and opportunistic infections in HIV-1, HIV-2 and HIV-1/2 dual seropositive patients in GuineaBissau. Infect Dis. 2016:48(8):604-11.

72. Bebell LM, Siedner MJ, Musinguzi N, Boum Y, Bwana BM, Muyindike W, Hunt PW, Martin JN, Bangsberg DR. Trends in one-year cumulative incidence of death between 2005 and 2013 among patients initiating antiretroviral therapy in Uganda. Int J STD AIDS. 2017;28(8):800-7.

73. Giri PA, Deshpande JD, Phalke DB. Prevalence of pulmonary tuberculosis among HIV positive patients attending antiretroviral therapy clinic. North Am J Med Sci. 2013;5(6):367-70.

74. McCarthy KM, Morgan J, Wannemuehler KA, Mirza SA, Gould SM, Mhlongo N, Moeng P, Maloba BR, Crewe-Brown HH, Brandt ME, et al. Population-based surveillance for cryptococcosis in an antiretroviralnaive South African province with a high HIV seroprevalence. AIDS. 2006;20(17):2199-206.

75. Oyella J, Meya D, Bajunirwe F, Kamya MR. Prevalence and factors associated with cryptococcal antigenemia among severely immunosuppressed HIVinfected adults in Uganda: a cross-sectional study. J Int AIDS Soc. 2012;15(1).

76. Tadege M. Time to death predictors of HIV/AIDS infected patients on antiretroviral therapy in Ethiopia. BMC Res Notes. 2018;11(1).

77. Asiimwe SB, Laker-Oketta M, Bennett J, Mocello A, Glidden D, Haberer J, Bwana $M$, Hunt P, Bangsberg D, Mbidde E et al: Impact of Kaposi sarcoma on survival in HIV-infected African adults on antiretroviral therapy. In: Topics in Antiviral Medicine vol. 22; 2014: 51.

78. Herce ME, Kalanga N, Crocker JT, Wroe EB, Keck JW, Chingoli FD, Gopal S, Bazile J, Beste JA, Rigodon J: HIV-associated Kaposi sarcoma treated with chemotherapy and ART in rural Malawi. Topics in Antiviral Medicine 2015, 23((Chingoli F.D.) Ministry of Health of the Republic of Malawi, Neno, Malawi):319-320.

79. Kilama BK, Moshiro C, Todd J, Ramadhani A, Mmbando D: Patient level findings: Pre-ART mortality and its determinants in Tanzania public-driven HIV care program (2004-2011). Topics in Antiviral Medicine 2015, 23((Todd J.)
London School of Hygiene and Tropical Medicine, London, United Kingdom):497-498.

80. Umanah T, Ncayiyana J, Padanilam X, Nyasulu PS: Outcomes of multidrug resistant tuberculosis treatment among human immunodeficiency virus coinfected patients taking anti-retroviral treatment at Sizwe Tropical Disease Hospital Johannesburg, South Africa. International Journal of Infectious Diseases 2016, 45((Nyasulu P.S.) Monash University, Johannesburg, Gauteng, South Africa):403.

81. Adebamowo SN, Adebamowo CA, Odutola M, Famooto A, Adebayo A, Alabi B, Obende K, Offiong R, Ologun S, Achara P, et al. Incidence, persistence, and determinants of human papillomavirus: a prospective cohort study of HIV-negative Nigerian women. J Glob Oncol. 2017;3(2):39S$40 \mathrm{~S}$.

82. Hector J, Vinikoor MJ, Musukuma K, Chilengi R, Jefferys L, Hobbins MA, Davies MA, Egger M, Wandeler G. Mortality of HIV/HBV coinfected patients on art in urban and rural Southern Africa. Topics Antivir Med. 2017;25(1): 241s.

83. Argemi X, Dara S, You S, Mattei JF, Courpotin C, Simon B, Hansmann Y, Christmann D, Lefebvre N. Impact of malnutrition and social determinants on survival of HIV-infected adults starting antiretroviral therapy in resourcelimited settings. AIDS. 2012;26(9):1161-6.

84. Benova L, Fielding K, Greig J, Nyang'wa BT, Casas EC, da Fonseca MS, du Cros P. Association of BMl category change with TB treatment mortality in HIV-positive smear-negative and extrapulmonary TB patients in Myanmar and Zimbabwe. PLoS One. 2012;7(4).

85. Choun K, Thai S, Pe R, Lorent N, Lynen L, van Griensven J. Incidence and risk factors for tuberculosis in HIV-infected patients while on antiretroviral treatment in Cambodia. Trans R Soc Trop Med Hyg. 2013;107(4):235-42.

86. Sharma A, Hoover DR, Shi Q, Gustafson D, Plankey MW, Hershow RC, Tien PC, Golub ET, Anastos K. Relationship between body mass index and mortality in HIV-infected HAART users in the women's interagency HIV study. PLoS One. 2015;10(12).

87. Kumar N, Aithal S, Unnikrishnan B, Ramapuram J, Thapar R, Mithra P, Kulkarni $\mathrm{V}$, Holla R. Predictors of mortality among a cohort of HIV/AIDS patients on anti-retroviral therapy in coastal South India. HIV AIDS Rev. 2017; 16(1):18-23.

88. Jiang J, Qin X, Liu H, Meng S, Abdullah AS, Huang J, Qin C, Liu Y, Huang Y, Qin F, et al. An optimal BMl range associated with a lower risk of mortality among HIV-infected adults initiating antiretroviral therapy in Guangxi, China. Sci Rep. 2019;9(1)

89. Frigati LJ, Kranzer K, Cotton MF, Schaaf HS, Lombard CJ, Zar HJ. The impact of isoniazid preventive therapy and antiretroviral therapy on tuberculosis in children infected with HIV in a high tuberculosis incidence setting. Thorax. 2011;66(6):496-501.

90. Ebissa G, Deyessa N, Biadgilign S. Predictors of early mortality in a cohort of HIV-infected children receiving high active antiretroviral treatment in public hospitals in Ethiopia. AIDS Care. 2015;27(6):723-30.

91. Liotta G, Mancinelli S, Nielsen-Saines K, Gennaro E, Gennaro E, Scarcella P, Magid NA, Germano P, Jere H, Guidotti G, et al. Reduction of maternal mortality with highly active antiretroviral therapy in a large cohort of HIVinfected pregnant women in Malawi and Mozambique. PLoS One. 2013;8(8): e71653.

92. Li N, Matchi E, Spiegelman D, Chalamilla G, Hertzmank E, Sando D, Sando MM, Liu E, Muya A, Fawzi W. Maternal mortality among HIV-infected pregnant women in Tanzania. Acta Obstet Gynecol Scand. 2014;93(5):463-8.

93. Woodd SL, Kelly P, Koethe JR, Praygod G, Rehman AM, Chisenga M, Siame J, Heimburger DC, Friis H, Filteau S. Risk factors for mortality among malnourished HIV-infected adults eligible for antiretroviral therapy. BMC Infect Dis. 2016;16(1).

94. Chandrasekhar A, Gupta A. Nutrition and disease progression pre-highly active antiretroviral therapy (HAART) and post-HAART: can good nutrition delay time to HAART and affect response to HAART? Am J Clin Nutr. 2011; 94(6):1703S-15S.

95. Kendi C, Penner J, Koech J, Nyonda M, Cohen CR, Bukusi EA, Ngugi E, Meyer $A C L$. Predictors of outcome in routine care for Cryptococcal meningitis in Western Kenya: lessons for HIV outpatient care in resource-limited settings. Postgrad Med J. 2013;89(1048):73-7.

96. Sabasaba A, Mwambi H, Somi G, Ramadhani A, Mahande MJ. Effect of isoniazid preventive therapy on tuberculosis incidence and associated risk factors among HIV infected adults in Tanzania: a retrospective cohort study. BMC Infect Dis. 2019;19(1). 
97. Kyeyune R, Saathoff E, Ezeamama AE, Löscher T, Fawzi W, Guwatudde D. Prevalence and correlates of cytopenias in HIV-infected adults initiating highly active antiretroviral therapy in Uganda. BMC Infect Dis. 2014;14(1).

98. Palombi L, Marazzi MC, Guidotti G, Germano P, Buonomo E, Scarcella P, Doro Altan A, Zimba Ida V, San Lio MM, De Luca A. Incidence and predictors of death, retention, and switch to second-line regimens in antiretroviral- treated patients in sub-Saharan African sites with comprehensive monitoring availability. Clin Infect Dis. 2009;48(1):115-22.

99. Jerene D, Endale A, Hailu Y, Lindtjøorn B. Predictors of early death in a cohort of Ethiopian patients treated with HAART. BMC Infect Dis. 2006;6.

100. Johannessen A, Naman E, Ngowi BJ, Sandvik L, Matee Ml, Aglen HE, Gundersen SG, Bruun JN. Predictors of mortality in HIV-infected patients starting antiretroviral therapy in a rural hospital in Tanzania. BMC Infect Dis. 2008;8:52

101. Dao CN, Peters PJ, Kiarie JN, Zulu I, Muiruri P, Ong'Ech J, Mutsotso W, Potter D, Njobvu L, Stringer JSA, et al. Hyponatremia, hypochloremia, and hypoalbuminemia predict an increased risk of mortality during the first year of antiretroviral therapy among HIV-infected Zambian and Kenyan women. AIDS Res Hum Retrovir. 2011;27(11):1149-55.

102. Masiira B, Baisley K, Mayanja BN, Kazooba P, Maher D, Kaleebu P. Mortality and its predictors among antiretroviral therapy naïve HIV-infected individuals with CD4 cell count $\geq 350$ cells/mm(3) compared to the general population: data from a population-based prospective HIV cohort in Uganda. Glob Health Action. 2014;7:21843.

103. Chen SC, Yu JK, Harries AD, Bong CN, Kolola-Dzimadzi R, Tok TS, King CC, Wang JD. Increased mortality of male adults with AIDS related to poor compliance to antiretroviral therapy in Malawi. Trop Med Int Health. 2008; 13(4):513-9.

104. Sieleunou I, Souleymanou M, Schönenberger AM, Menten J, Boelaert M. Determinants of survival in AIDS patients on antiretroviral therapy in a rural Centre in the far-North Province, Cameroon. Trop Med Int. 2009;14(1):36-43.

105. Geng EH, Bwana MB, Muyindike W, Glidden DV, Bangsberg DR, Neilands TB, Bernheimer I, Musinguzi N, Yiannoutsos CT, Martin JN. Failure to initiate antiretroviral therapy, loss to follow-up and mortality among HIV-infected patients during the pre-ART period in Uganda. J Acquir Immune Defic Syndr. 2013;63(2):e64-71.

106. Hoffmann CJ, Fielding KL, Johnston V, Charalambous S, Innes C, Moore RD, Chaisson RE, Grant AD, Churchyard GJ. Changing predictors of mortality over time from CART start: implications for care. J Acquir Immune Defic Syndr. 2011;58(3):269-73.

107. Maman D, Pujades-Rodriguez M, Nicholas S, McGuire M, Szumilin E, Ecochard R, Etard JF. Response to antiretroviral therapy: improved survival associated with CD4 above 500 cells/Ml. AIDS. 2012;26(11):1393-8.

108. Stringer JS, Zulu I, Levy J, Stringer EM, Mwango A, Chi BH, Mtonga V, Reid S, Cantrell RA, Bulterys M, et al. Rapid scale-up of antiretroviral therapy at primary care sites in Zambia: feasibility and early outcomes. JAMA. 2006; 296(7):782-93.

109. Pac L, Horwitz MM, Namutebi AM, Auerbach BJ, Semeere A, Namulema T, Schwarz M, Bbosa R, Muruta A, Meya DB, et al. Implementation and operational research: integrated pre-antiretroviral therapy screening and treatment for tuberculosis and cryptococcal antigenemia. J Acquir Immune Defic Syndr. 2015;68(5):e69-76.

110. Tchounga BK, Hønge BL, Eholie SP, Coffie PA, Jespersen S, Wejse C, Dabis F, Geoffrey GS, Ekouevi DK. Effect of sex and age on outcomes among HIV-2infected patients starting antiretroviral therapy in West Africa. AIDS. 2016; 30(17):2707-14.

111. Otwombe KN, Petzold M, Modisenyane T, Martinson NA, Chirwa T. Factors associated with mortality in HIV-infected people in rural and urban South Africa. Glob Health Action. 2014;7(1).

112. Zachariah R, Fitzgerald M, Massaquoi M, Pasulani O, Arnould L, Makombe S, Harries AD. Risk factors for high early mortality in patients on antiretroviral treatment in a rural district of Malawi. AIDS. 2006;20(18):2355-60.

113. Worodria W, Massinga-Loembe M, Mayanja-Kizza H, Namaganda J, Kambugu A, Manabe YC, Kestens L, Colebunders R. Antiretroviral treatmentassociated tuberculosis in a prospective cohort of HIV-infected patients starting ART. Clin Dev Immunol. 2011;2011:758350.

114. Nicholas S, Sabapathy K, Ferreyra C, Varaine F, Pujades-Rodríguez M. Incidence of tuberculosis in HIV-infected patients before and after starting combined antiretroviral therapy in 8 sub-Saharan African HIV programs. J Acquir Immune Defic Syndr. 2011;57(4):311-8.
115. Liu E, Makubi A, Drain P, Spiegelman D, Sando D, Li N, Chalamilla G, Sudfeld $C R$, Hertzmark E, Fawzi WW. Tuberculosis incidence rate and risk factors among HIV-infected adults with access to antiretroviral therapy. AIDS. 2015; 29(11):1391-9.

116. Chang CA, Meloni ST, Eisen G, Chaplin B, Akande P, Okonkwo P, Rawizza HE, Tchetgen ET, Kanki PJ. Tuberculosis incidence and risk factors among human immunodeficiency virus (HIV)-infected adults receiving antiretroviral therapy in a large HIV program in Nigeria. Open Forum Infect Dis. 2015;2(4): $1-11$

117. Bjerrum S, Oliver-Commey J, Kenu E, Lartey M, Newman MJ, Addo KK, Hilleman D, Andersen AB, Johansen IS. Tuberculosis and non-tuberculous mycobacteria among HIV-infected individuals in Ghana. Trop Med Int Health. 2016;21(9):1181-90.

118. Mupfumi L, Moyo S, Molebatsi K, Thami PK, Anderson M, Mogashoa T, Iketleng T, Makhema J, Marlink R, Kasvosve I, et al. Immunological nonresponse and low hemoglobin levels are predictors of incident tuberculosis among HIV-infected individuals on Truvada-based therapy in Botswana. PLoS One. 2018;13(1).

119. Melkamu H, Seyoum B, Dessie Y. Determinants of tuberculosis infection among adult HIV-positives attending clinical care in Western Ethiopia: a case-control study. AIDS Res Treat. 2013;2013:279876.

120. Gedle D, Kumera G, Eshete T, Ketema K, Adugna H, Feyera F. Intestinal parasitic infections and its association with undernutrition and CD4 T cell levels among HIV/AIDS patients on HAART in Butajira, Ethiopia. J Health Popul Nutr. 2017;36(1):15.

121. Ageru TA, Koyra MM, Gidebo KD, Abiso TL. Anemia and its associated factors among adult people living with human immunodeficiency virus at Wolaita Sodo University teaching referral hospital. PLoS One. 2019;14(10): e0221853.

122. Chen YN, Wall KM, Fofana K, Navarro-Colorado C. Nutrition indicators as potential predictors of AIDS-defining illnesses among ARV-naïve HIVpositive adults in Kapiri Mposhi, Zambia 2008-2009. PLoS One. 2019;14(7).

123. Hussen S, Belachew T, Hussein N. Nutritional status of HIV clients receiving HAART: Its omplication on occurrence of opportunistic infection. The Open Public Health J. 2017;10(1).

124. Umanah T, Ncayiyana J, Padanilam X, Nyasulu PS. Treatment outcomes in multidrug resistant tuberculosis-human immunodeficiency virus co-infected patients on anti-retroviral therapy at Sizwe tropical disease hospital Johannesburg, South Africa. BMC Infect Dis. 2015;15:478.

125. Hughes S, Kelly P. Interactions of malnutrition and immune impairment, with specific reference to immunity against parasites. Parasite Immunol. 2006;28(11):577-88.

126. Candiani TM, Pinto J, Cardoso CA, Carvalho IR, Dias AC, Carneiro M, Goulart EA. Impact of highly active antiretroviral therapy (HAART) on the incidence of opportunistic infections, hospitalizations and mortality among children and adolescents living with HIV/AIDS in Belo Horizonte, Minas Gerais state, Brazil. Cad Saude Publica. 2007;23(Suppl 3):S414-23.

127. Mermin J, Were W, Ekwaru JP, Moore D, Downing R, Behumbiize P, Lule JR, Coutinho A, Tappero J, Bunnell R. Mortality in HIV-infected Ugandan adults receiving antiretroviral treatment and survival of their HIV-uninfected children: a prospective cohort study. Lancet. 2008;371(9614):752-9.

128. Berhe N, Tegabu D, Alemayehu M. Effect of nutritional factors on adherence to antiretroviral therapy among HIV-infected adults: a case control study in northern Ethiopia. BMC Infect Dis. 2013;13:233.

129. Young S, Wheeler AC, McCoy SI, Weiser SD. A review of the role of food insecurity in adherence to care and treatment among adult and pediatric populations living with HIV and AIDS. AIDS Behav. 2014;18(Suppl 5):S505-15.

130. lacob SA, lacob DG, Jugulete G. Improving the adherence to antiretroviral therapy, a difficult but essential task for a successful hiv treatment-clinical points of view and practical considerations. Front Pharmacol. 2017;8:831.

131. Rai S, Mahapatra B, Sircar S, Raj PY, Venkatesh S, Shaukat M, Rewari BB. Adherence to antiretroviral therapy and its effect on survival of HIV-infected individuals in Jharkhand, India. PLoS One. 2013;8(6):e66860.

132. Biset Ayalew M. Mortality and its predictors among HIV infected patients taking antiretroviral treatment in Ethiopia: a systematic review. AIDS Res Treat. 2017;2017.

133. Ahmed M, Merga $H$, Jarso $H$. Predictors of virological treatment failure among adult HIV patients on first-line antiretroviral therapy in Woldia and Dessie hospitals, Northeast Ethiopia: a case-control study. BMC Infect Dis. 2019;19(1):305. 
134. Pujades-Rodriguez M, Balkan S, Arnould L, Brinkhof MA, Calmy A. Treatment failure and mortality factors in patients receiving second-line HIV therapy in resource-limited countries. J Am Med Assoc. 2010;304(3):303-12.

135. Pettersen PS, Brox IK, Naman E, Bruun JN, Dyrhol-Riise AM, Troseid M, Johannessen A. Antiretroviral treatment failure predicts mortality in rural Tanzania. Int J STDs AIDS. 2015;26(9):633-9.

136. Scrimshaw NS. Historical concepts of interactions, synergism and antagonism between nutrition and infection. J Nutr. 2003;133(1):316S-21S.

137. Walson JL, Berkley JA. The impact of malnutrition on childhood infections. Curr Opin Infect Dis. 2018;31(3):231.

138. Lonnroth K, Williams BG, Cegielski P, Dye C. A consistent log-linear relationship between tuberculosis incidence and body mass index. Int J Epidemiol. 2010;39(1):149-55.

139. Bourke CD, Berkley JA, Prendergast AJ. Immune dysfunction as a cause and consequence of malnutrition. Trends Immunol. 2016:37(6):386-98

140. Padmapriyadarsini C, Shobana M, Lakshmi M, Beena T, Swaminathan S. Undernutrition \& tuberculosis in India: situation analysis \& the way forward. Indian J Med Res. 2016;144(1):11-20.

141. Chandrasekaran P, Saravanan N, Bethunaickan R, Tripathy S. Malnutrition: modulator of immune responses in tuberculosis. Front Immunol. 2017;8: 1316.

142. Gupta KB, Gupta R, Atreja A, Verma M, Vishvkarma S. Tuberculosis and nutrition. Lung India Official Organ Indian Chest Soc. 2009;26(1):9.

143. FAO I, \& WFP, : \& WFP (world food Programme). In: Achieving Zero Hunger The critical role of investment in social protection and agriculture Rome, FAO. Edited by Nations FaAOotU; 2015.

144. World Health Organization. Guideline: nutritional care and support for patients with tuberculosis. Geneva: World Health Organization; 2013.

145. United Nations: World Bank list of economies (June 2019) available at https://hupo.org/resources/Documents/World\%20Bank\%20list\%20of\%2 Oeconomies\%20(June\%202019).pdf. Accessed 18 Feb 2020. 2019.

146. Zanoni BC, Gandhi RT. Update on opportunistic infections in the era of effective antiretroviral therapy. Infect Dis Clinic North Am. 2014;28(3):501-18.

147. The Ethiopian Federal Ministry of Health: National Comprehensive HIV Prevention, Care and Treatment Training for Health care Providers. In.; 2017.

148. Filteau S, PrayGod G, Kasonka L, Woodd S, Rehman AM, Chisenga M, Siame J, Koethe JR, Changalucha J, Michael D, et al. Effects on mortality of a nutritional intervention for malnourished HIV-infected adults referred for antiretroviral therapy: a randomised controlled trial. BMC Med. 2015;13:17.

149. Mallewa J, Szubert AJ, Mugyenyi P, Chidziva E, Thomason MJ, Chepkorir P, Abongomera G, Baleeta K, Etyang A, Warambwa C, et al. Effect of ready-touse supplementary food on mortality in severely immunocompromised HIVinfected individuals in Africa initiating antiretroviral therapy (REALITY): an open-label, parallel-group, randomised controlled trial. Lancet HIV. 2018;5(5): e231-40.

150. PrayGod G, Friis H, Filteau S. Nutritional support to reduce mortality in patients with HIV? Lancet HIV. 2018;5(5):e202-4.

151. World Health Organization: Essential prevention and care interventions for adults and adolescents living with HIV in resource-limited settings available at https://apps.who.int/iris/bitstream/handle/10665/44033/9789241596701_ eng.pdf. Accessed 19 Feb 2020; 2008.

152. Lawn SD, Harries AD, Anglaret X, Myer L, Wood R. Early mortality among adults accessing antiretroviral treatment programmes in sub-Saharan Africa. AIDS. 2008;22(15):1897-908.

\section{Publisher's Note}

Springer Nature remains neutral with regard to jurisdictional claims in published maps and institutional affiliations.

Ready to submit your research? Choose BMC and benefit from:

- fast, convenient online submission

- thorough peer review by experienced researchers in your field

- rapid publication on acceptance

- support for research data, including large and complex data types

- gold Open Access which fosters wider collaboration and increased citations

- maximum visibility for your research: over $100 \mathrm{M}$ website views per year

At $\mathrm{BMC}$, research is always in progress.

Learn more biomedcentral.com/submissions 